\title{
Total Dissolved Gas Monitoring in Chum Salmon Spawning Gravels Below Bonneville Dam
}

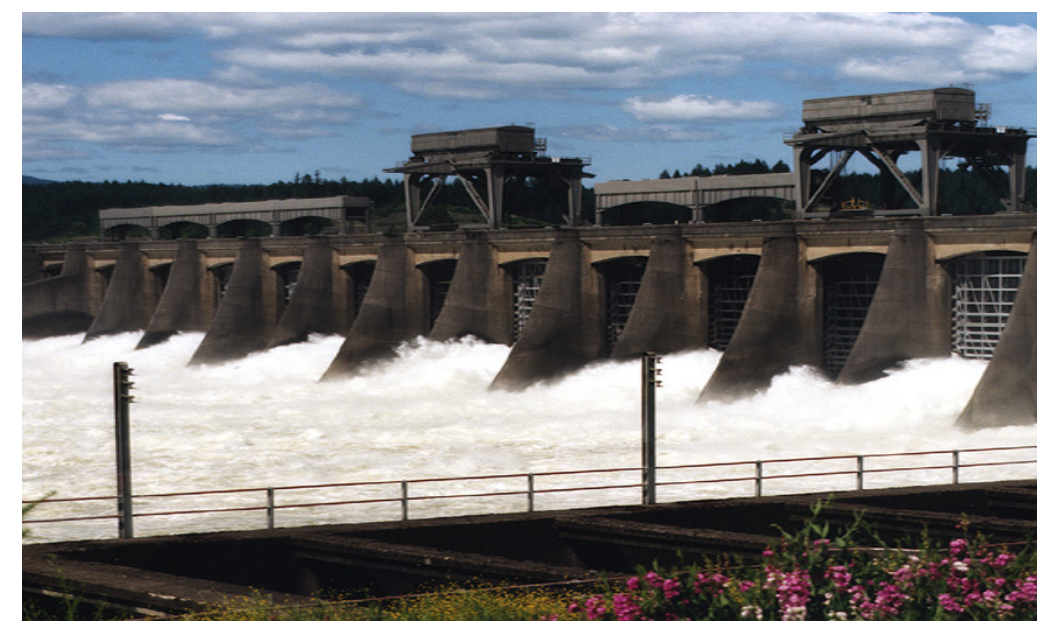
E. V. Arntzen
J. L. Panther
D. R. Geist
E. M. Dawley

Final Report

January 2007

Prepared for the U.S. Army Corps of Engineers

Portland District, Portland, Oregon

Under a Related Services Agreement

with the U.S. Department of Energy

Contract DE-AC05-76RL01830

\section{Pacific Northwest \\ National Laboratory}

Operated by Battelle for the

U.S. Department of Energy 


\title{
Total Dissolved Gas Monitoring in Chum Salmon Spawning Gravels Below Bonneville Dam
}

\author{
E. V. Arntzen \\ J. L. Panther \\ D. R. Geist \\ E. M. Dawley ${ }^{(a)}$
}

January 2007

Prepared for

the U.S. Department of Energy

under Contract DE-AC05-76RL01830

Pacific Northwest National Laboratory

Richland, Washington 99352

(a) National Oceanic and Atmospheric Administration,

National Marine Fisheries Service (Ret.) 



\section{Summary}

At the request of the U.S. Army Corps of Engineers (Portland District), Pacific Northwest National Laboratory (PNNL) conducted research to determine whether total dissolved gas concentrations are elevated in chum salmon redds during spring spill operations at Bonneville Dam. The study involved monitoring the total dissolved gas levels at egg pocket depth and in the river at two chum salmon spawning locations downstream from Bonneville Dam.

Dissolved atmospheric gas supersaturation generated by spill from Bonneville Dam may diminish survival of chum salmon (Oncorhynchus keta) when sac fry are still present in the gravel downstream from Bonneville Dam. However, no previous work has been conducted to determine whether total dissolved gas (TDG) levels are elevated during spring spill operations within incubation habitats. The guidance used by hydropower system managers to provide protection for pre-emergent chum salmon fry has been to limit TDG to $105 \%$ after allowing for depth compensation. A previous literature review completed in early 2006 shows that TDG levels as low as $103 \%$ have been documented to cause mortality in sac fry. Our study measured TDG in the incubation environment to evaluate whether these levels were exceeded during spring spill operations.

Total dissolved gas levels were measured within chum salmon spawning areas near Ives Island and Multnomah Falls on the Columbia River. Water quality sensors screened at egg pocket depth and to the river were installed at both sites. At each location, we also measured dissolved oxygen, temperature, specific conductance, and water depth to assist with the interpretation of TDG results. Total dissolved gas was depth-compensated to determine when levels were high enough to potentially affect sac fry.

Results of the monitoring included the following findings:

- $\quad$ Both the Ives and Multnomah Falls sites were influenced by groundwater. However, at Multnomah Falls, despite significant fluctuations in river concentrations of total dissolved gas, dissolved oxygen, and temperature, egg pocket concentrations remained stable, suggesting relatively constant groundwater discharge there. In contrast, egg pocket responses at the Ives Island site fluctuated widely in response to changes in river water quality, suggesting spawning gravels in the Ives area are in much closer contact with river water.

- We considered TDG levels during times of voluntary and involuntary spill and found that from April through August 2006, there was no statistical difference.

- Depth-compensated TDG values remained less than $103 \%$ at all the sites we monitored from the initiation of spring spill through the completion of chum emergence.

- 2006 represents a relatively high-water year during which TDG could generally be depthcompensated to mitigate negative impacts to sac fry, and water levels stayed above the compensation depth. However, water level data for other years (e.g., 2005 when the river depth in the Ives area dropped below the compensation depth 39\% of the time from April 4 through May 5) suggest TDG could have a significant impact during lower-water years. 
Whether elevated levels of TDG would result in negative impacts to sac fry is purely speculative because no specific studies of elevated TDG have been conducted on chum salmon sac fry. We recommend that research be conducted to evaluate the effects of total dissolved gas on incubating chum salmon sac fry. We also recommend monitoring total dissolved gas at Ives Island and Multnomah Falls during normal- to low-water years when depth compensation will be reduced and impacts to sac fry would be maximized. 


\section{Acknowledgments}

This project was funded by the U.S. Army Corps of Engineers, Portland District. Thanks to scuba divers John Southard, Sue Southard, and John Vavrinec who assisted in sensor retrieval. Berhon Dibrani and Cherylyn Tunnicliffe assisted with sensor calibration and preparation. Corey Duberstein and Brian Miller assisted with field work. Thanks to Kathleen McGrath for reviewing the report. 



\section{Contents}

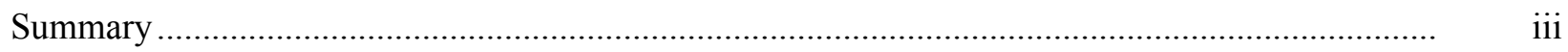

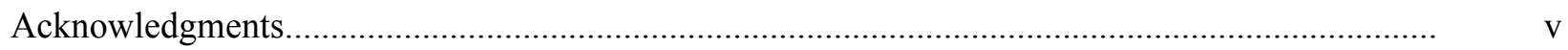

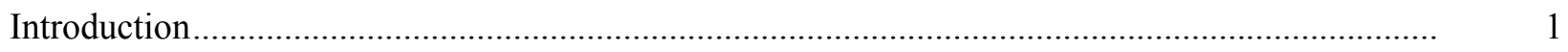

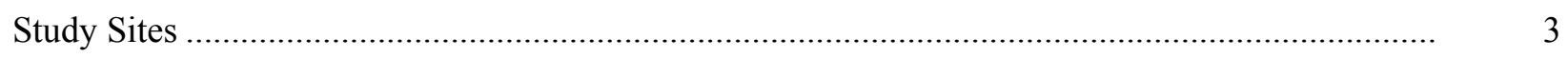

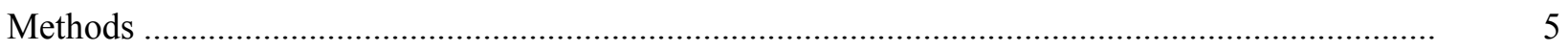

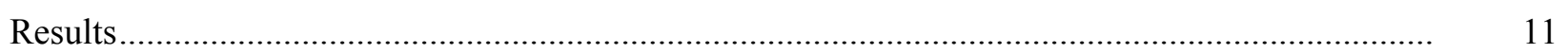

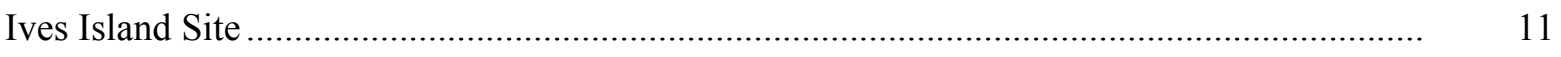

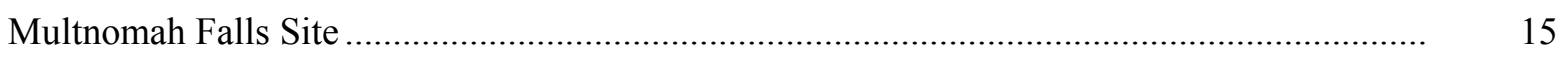

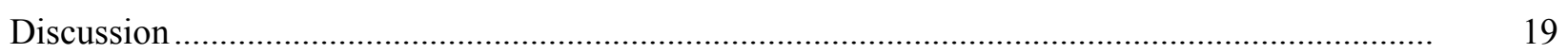

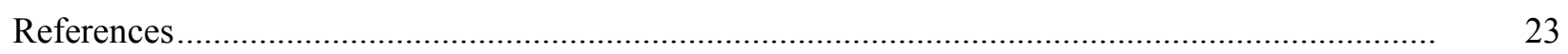

Appendix A - Total Dissolved Gas Sensor Membrane Quality Assurance Tests ......... CD inside back cover Appendix B - Water Quality Data ......................................................................... inside back cover

\section{Figures}

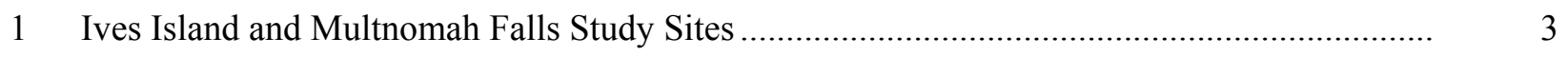

2 Piezometer Stations Near Ives Island and Multnomah Falls...............................................

3 River and Hyporheic Piezometer Construction................................................................ 5

4 Examples of Functional Versus Damaged Membrane Responses During Quality Assurance Tests Using Compressed Air and Soda Water..................................................... 8

5 Total Dissolved Gas Monitoring Stations Downstream of Bonneville Dam ........................... 9

6 Comparison of 2006 TDG Values Obtained at PNNL Monitoring Stations and

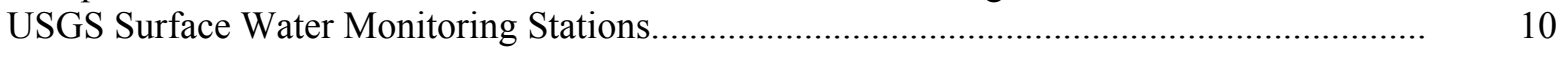

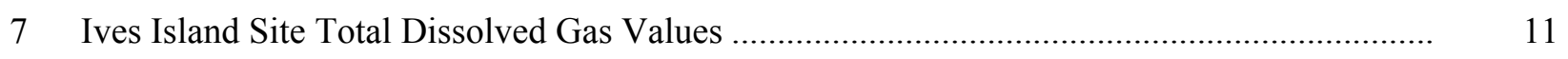

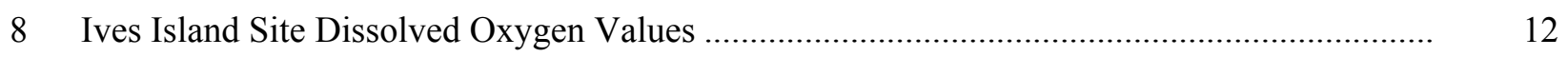

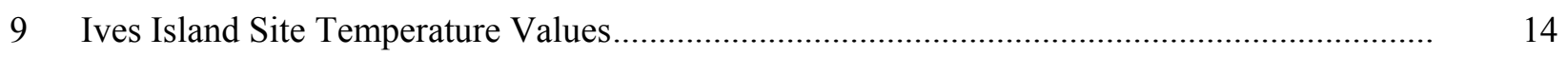

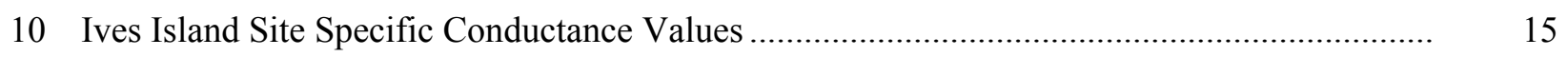

11 Multnomah Falls Site Total Dissolved Gas Values ............................................................. 16

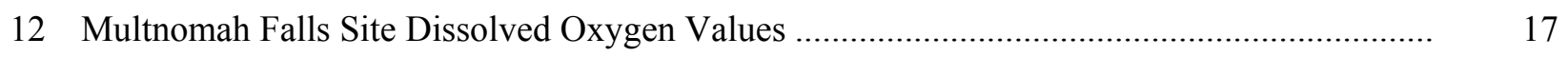

13 Multnomah Falls Site Temperature Values...................................................................... 17 


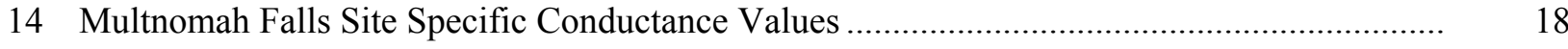

15 Water Depth Above the Egg Pocket and the Compensation Depth Near Ives Pair 1 During Spring Runoff in 2004, 2005, and 2006.

\section{Table}

1 Minisonde Water Quality Sensor Specifications 


\section{Introduction}

Gas supersaturation generated by spill from dams on the Columbia River was first acknowledged as an environmental concern in 1965 (Ebel 1969). Following extensive assessment, the U.S. Environmental Protection Agency (EPA) adopted a nationwide water quality criterion maximum of $110 \%$ total dissolved gas saturation (TDGS) for the protection of aquatic life (NAS/NAE 1973). The 110\% TDGS criterion remains in effect (EPA 1987).

During the 1970s and 1980s, considerable research was conducted on effects of gas supersaturation on aquatic life, primarily juvenile salmonids. Relatively little attention was given to other species or salmonid adults, sac fry, or eggs. Also during that time, the addition of large water storage reservoirs and modifications to existing dams (including spillway flow deflectors and increased hydroelectric capacity) reduced total dissolved gas (TDG) levels during both voluntary and involuntary spill. Ebel and Raymond (1976) and Weitkamp and Katz (1980) summarized research conducted during that period. Beginning in the early 1990s, water quality agencies issued limited water quality waivers to facilitate spill for downstream migration of juvenile salmonids. Monitoring studies over a 10-year period and TDG modeling efforts, reviewed extensively in the 1995 and 2000 Biological Opinions, indicated that TDGS levels between $110 \%$ and $120 \%$ had minimal impacts on aquatic biota in river environments (NOAA 1995, 2000). Therefore, waivers to the water quality criterion were granted that permitted up to $115 \%$ TDGS in downstream reaches where spill and powerhouse flows were mixed and up to 120\% TDGS in dam tailraces where flows from spillways were separated from those of powerhouse discharge (NOAA 1995).

Gas supersaturation as a water quality issue has resurfaced recently (USACE et al. 2004) as concerns have grown regarding acute and chronic effects of TDG on salmonids, resident fish species, and other aquatic organisms. Of particular concern are TDG levels in the salmon egg incubation environment during spill. Elevated TDG levels within salmon redds may diminish survival of chum (Oncorhynchus keta) and fall Chinook (O. tshawytscha) salmon progeny downstream from Bonneville Dam (McGrath et al. 2006).

Several spill operations occur at Bonneville Dam in the early spring when chum salmon sac fry are still present in the gravel. Spill occurs during March for the Spring Creek hatchery release and during April for juvenile migration needs at Bonneville Dam and in the lower river. The guidance managers have used to provide protection for pre-emergent chum salmon fry has been to limit TDG to $105 \%$ after allowing for depth compensation. No data, new or otherwise, are currently available on TDG levels in incubation habitats or on TDG effects on incubating chum salmon. However, a recent literature review shows that TDG levels as low as $103 \%$ have been documented to cause mortality in sac fry (McGrath et al. 2006).

During adequate water years, water depths over chum salmon redds are sufficient to provide the depth compensation necessary for chum salmon sac fry to avoid the effects of elevated TDG (provided surface water TDG levels do not exceed $120 \%$ per the current guidelines). However, during low water years, concerns about the effects of TDG on pre-emergent chum salmon fry have forced operators to choose between either providing spill to improve juvenile fish passage or limiting spill to protect incubating chum salmon. Few data have been collected to evaluate the effects of TDG on chum salmon fry, and we were unable to locate any previous research evaluating exposure of salmonid fry to TDG within spawning gravels. Because chum salmon are spawning in environments very different from habitats previously 
studied, and because the presumed effects of elevated TDG on chum salmon sac fry are influencing spring spill management decisions at Bonneville Dam, current field-determined TDG concentrations are needed (McGrath et al. 2006).

The study documented in this report was conducted for the U.S. Army Corps of Engineers by Pacific Northwest National Laboratory. The study objective was to monitor the TDG levels at egg pocket depth and in the river at two chum salmon spawning locations downstream from Bonneville Dam to determine whether total dissolved gas concentrations are elevated in chum salmon redds during spring spill operations.

This report provides detailed descriptions of the two study sites downstream of Bonneville Dam, as well as the equipment and procedures employed to monitor the TDG levels at the study sites. Results of the monitoring at both sites are then presented in both text and graphics. The findings and recommendations for further research are discussed, followed by a listing of the references cited in the report. Appendix A provides all data from quality assurance tests conducted on total dissolved gas sensor membranes used in data collection. Appendix B contains all the water quality data collected during the 2006 monitoring period. Appendixes A and B are contained on the compact disk (CD) provided with the hardcopy version of this report on the inside back cover. 


\section{Study Sites}

Two major chum salmon spawning areas were selected for monitoring. One site was a side channel downstream from Bonneville Dam on the right bank north of Ives Island at river kilometer (rkm) 230, which is $4.3 \mathrm{~km}$ downstream from Bonneville Dam. The other site was on the left bank near Multnomah Falls at rkm 220, 14.8 km downstream from Bonneville Dam (Figure 1).

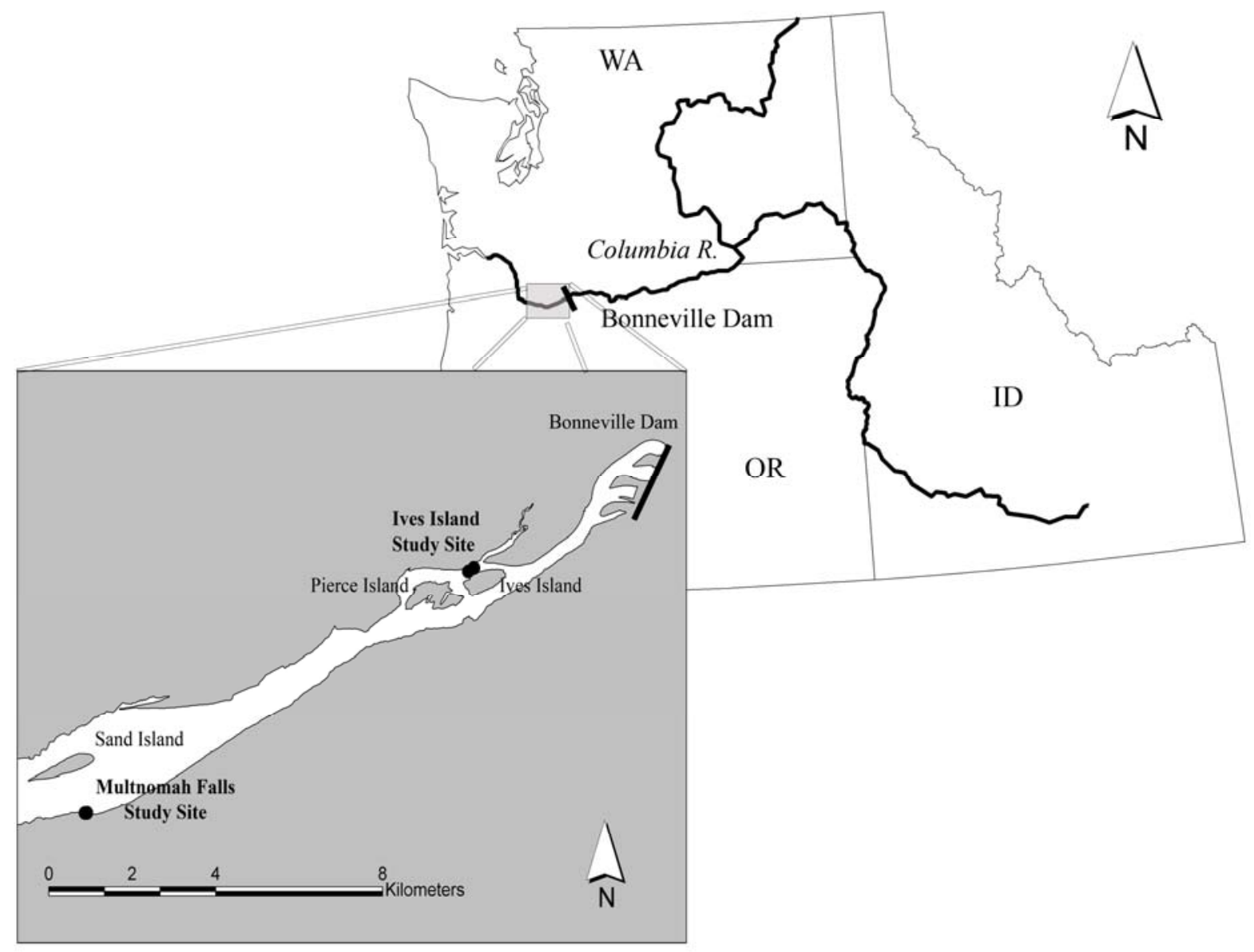

Figure 1. Ives Island and Multnomah Falls Study Sites

At each site, TDG sensors were deployed in the hyporheic zone at egg pocket depth and also in the river. The hyporheic zone is the area below the riverbed where groundwater interacts with surface water (Orghidan 1959). The TDG sensors were deployed inside piezometers (shallow wells), with screens exposed to either the hyporheic zone or the overlying river.

At the Ives Island site, we installed three pairs of piezometers, each pair at a different riverbed elevation. Our goal was to establish monitoring locations within chum salmon spawning areas at a range of riverbed elevations in order to collect representative data and also to increase the likelihood that some sensors could be recovered during high river discharge. Elevation data for chum salmon redds were available for the 2004 spawning season (J. Skalicky, Washington State Department of Fish and Wildlife, unpublished data). We compared these data to the elevation of the riverbed at our TDG monitoring 
stations to determine what percentage of the chum salmon redds in 2004 were at an elevation lower than each monitoring station (Figure 2). The first pair of piezometers (Ives 1) consisted of one river and one hyporheic piezometer installed in the middle of the side channel on the right bank. Seventy-five percent of 2004 chum salmon in the surrounding areas spawned at an elevation lower than Ives 1 . The second pair (Ives 2) was installed approximately $8 \mathrm{~m}$ farther away from the right bank and in shallower water than that at Ives 1. Approximately $96 \%$ of 2004 chum salmon spawned at an elevation lower than Ives 2 . The third pair (Ives 3) was installed approximately $150 \mathrm{~m}$ downstream of Ives 2 on the left bank of the bar (Figure 2). One hundred percent of 2004 chum salmon spawned at an elevation lower than Ives 3. Ives 3 was installed where the river was expected to form an eddy during high flows so that dive operations could continue and data could be collected if water velocities were too high to sample Ives 1 or Ives 2 .

One pair of river and hyporheic piezometers was installed at the Multnomah Falls site on the left bank side of the river (pair 1); a single hyporheic piezometer was emplaced $58 \mathrm{~m}$ downstream of the pair of piezometers (Figure 2). Because water velocities were less a concern at the Multnomah Falls site and redd elevation data were not available, we centered the sampling stations within high-density chum salmon spawning areas (Figure 2).
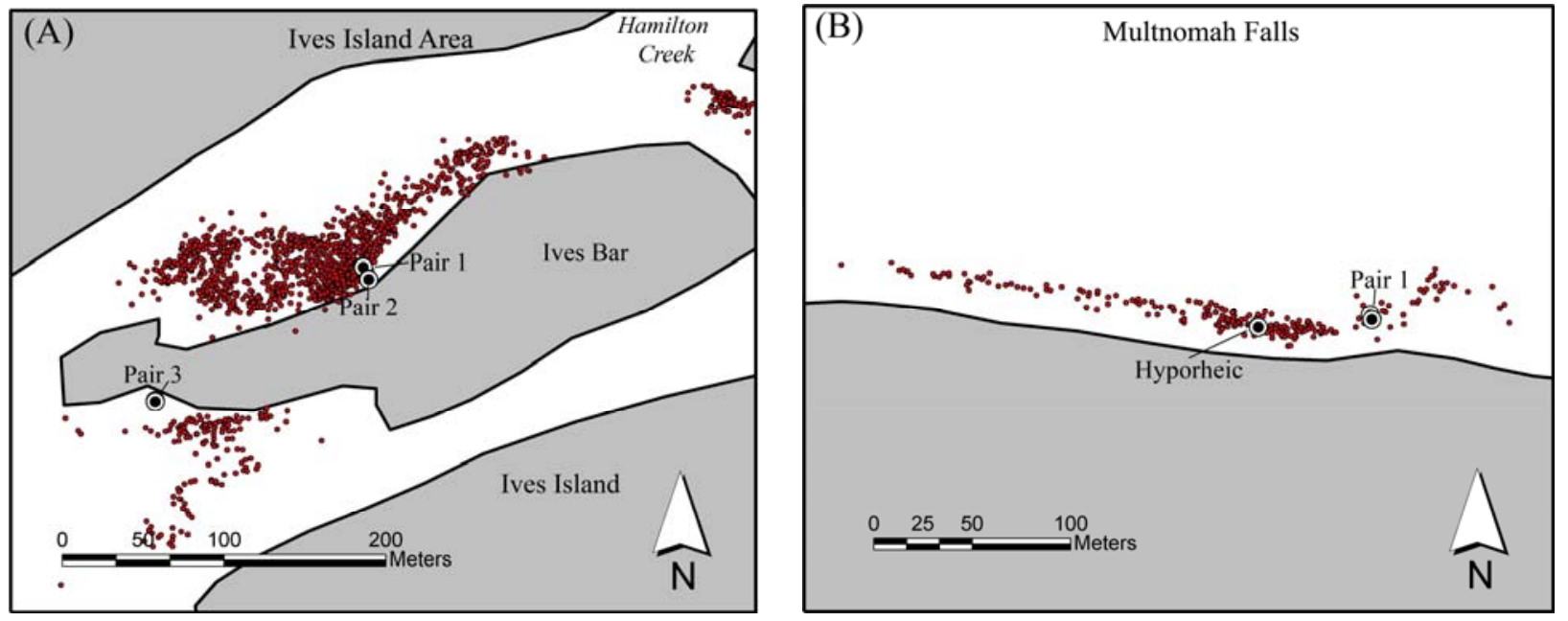

Figure 2. Piezometer Stations (white circles) Near (A) Ives Island and (B) Multnomah Falls. Red circles represent the chum salmon redds marked from 2000 through 2005 at Ives Island and from 2003 through 2004 at Multnomah Falls. 


\section{Methods}

Each piezometer consisted of a 115-cm length of galvanized pipe (6.0-cm outer diameter [OD], $5.3-\mathrm{cm}$ inner diameter [ID]) with male threads on both ends. A $30-\mathrm{cm}$ length on one end of the pipe was perforated uniformly and wrapped with a $30-\mathrm{cm}$ length of stainless steel screen with 0.32 -cm openings on top of 80-gauze stainless steel mesh. Both ends of the screens were welded to one end of the pipe, and a threaded drive point was attached to the other end. Flow was found to be too restricted through the piezometer; consequently, we drilled holes through the screens in line with the holes in the pipe. Each hyporheic piezometer was equipped with a $6.0-\mathrm{cm}$ threaded drive coupler and a $15.2-\mathrm{cm}$-long galvanized threaded riser attached to the end of the pipe directly above the screen (Figure 3). The riser allowed the $30-\mathrm{cm}$ length of screen to be driven below the surface of the riverbed and still have a threaded length of pipe for attachment of the sensor cap.

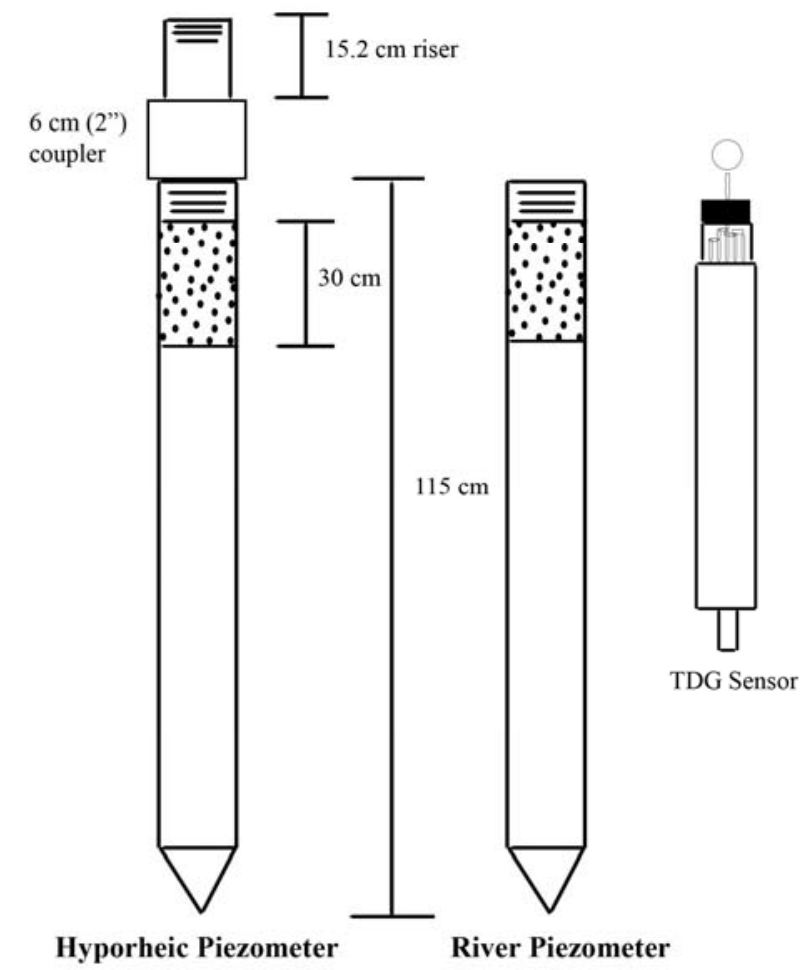

Figure 3. River and Hyporheic Piezometer Construction. The TDG sensors were deployed inside the piezometers.

We used a gasoline-powered jackhammer to drive the piezometers into the riverbed (Geist et al. 1998). A 6-cm segment of $2.5-\mathrm{cm}$ cold-rolled steel was placed in the drive point tip to absorb the impact of the internal drive rod and prevent the drive rod from becoming lodged inside the tip of the piezometer. The drive rod consisted of a $183-\mathrm{cm}$ length of $2.5-\mathrm{cm}-\mathrm{OD}$ cold-rolled steel. River piezometers were driven until the bottom of the screen was approximately $20 \mathrm{~cm}$ above the riverbed. Hyporheic piezometers were driven until the top of the screen was approximately $20 \mathrm{~cm}$ below the riverbed. After piezometers were installed, they were developed by removing fines with a hand pump. 
Finally, the locations of the piezometers were recorded with a Trimble ProXR global positioning system (GPS). Caps were placed on all piezometers to prevent sediment from accumulating in them prior to the installation of TDG sensors.

Eight Minisonde sensors (Hydrolab Corporation) were used to monitor water quality. Each Minisonde weighed $1.3 \mathrm{~kg}$ and measured $74.9 \mathrm{~cm}$ long with a 4.4-cm OD. Seven Minisondes were Model 5A, and one was a Minisonde Model 4A. Each Minisonde 5A included sensors to monitor dissolved oxygen (DO), specific conductance, depth, TDG, temperature, and salinity. The Minisonde 4A included the same features except for a dissolved oxygen sensor. Detailed specifications, including accuracies and resolutions, are listed in Table 1 for both Minisonde models. Three of the Minisondes placed in hyporheic piezometers were retrofitted with stirrers after laboratory tests suggested they were necessary to remove air bubbles from the total dissolved gas sensor. The stirrers consisted of a $1.27-\mathrm{cm}-$ wide revolving plastic blade attached to the Minisonde next to the TDG sensor. All Minisondes were powered using eight internal AA batteries.

Table 1. Minisonde Water Quality Sensor Specifications (Hydrolab Corporation 2006)

\begin{tabular}{||l|l|l|l||}
\hline \multicolumn{1}{|c|}{ Sensor } & \multicolumn{1}{|c|}{ Range } & \multicolumn{1}{c|}{ Stated Accuracy } & \multicolumn{1}{c||}{ Resolution } \\
\hline \hline Total dissolved gas & 400 to $1300 \mathrm{mmHG}$ & $\pm 0.1 \%$ of the span & $1.0 \mathrm{mmHg}$ \\
\hline $\begin{array}{l}\text { Luminescent dissolved } \\
\text { oxygen }\end{array}$ & 0 to $20 \mathrm{mg} / \mathrm{L}$ & $\begin{array}{l}0.1 \mathrm{mg} / \mathrm{L} @<8 \mathrm{mg} / \mathrm{L} \text { and } \\
\pm 0.2 \mathrm{mg} / \mathrm{L} @>8 \mathrm{mg} / \mathrm{L}\end{array}$ & $0.01 \mathrm{mg} / \mathrm{L}$ \\
\hline Specific conductance & 0 to $50 \mathrm{mS} / \mathrm{cm}$ & $\begin{array}{l} \pm 0.5 \% \text { of reading or } \pm 0.001 \\
\mathrm{mS} / \mathrm{cm}\end{array}$ & 4 digits \\
\hline Depth & 0 to $25 \mathrm{~m}$ (Minisonde $5 \mathrm{~A})$ & $\pm 0.05 \mathrm{~m}$ & $0.01 \mathrm{~m}$ \\
\hline Temperature & 0 to $100 \mathrm{~m}($ Minisonde $4 \mathrm{~A})$ & & $0.01^{\circ} \mathrm{C}$ \\
\hline
\end{tabular}

Each Minisonde was equipped with a 15.2-cm-long slotted deployment cap. We deployed the Minisondes by attaching a $0.64-\mathrm{cm}$ eyebolt to the stainless steel end of the deployment cap and attaching a $0.32-\mathrm{cm}-O D$ stainless steel cable to the eyebolt. The other end of the cable was attached to an expansion cap, which secured the sensor to the top of the piezometer. The expansion cap consisted of two 5.1-cm-OD plastic discs with threaded holes in the middle of them, surrounded by a rubber gasket. A stainless steel screw and wing nut were used to tighten the two plastic discs together, causing the rubber gasket to expand until it was tightly secured in the piezometer. A metal plate with holes in it was attached to the cap, and the cable was passed through the holes and secured to the cap by clamping it together with U-bolts. Minisondes were deployed with the sensor tips located in the center of the piezometer screen, pointed in an upward direction (Figure 3).

Prior to deployment, fully charged AA batteries were installed in all Minisondes. We programmed each Minisonde to log parameters including water level, temperature, salinity, total dissolved gas, dissolved oxygen (if applicable), and specific conductance. One measurement was recorded for each parameter every hour until the batteries were spent. Every two to three weeks from February 26 to May 7, 2006, the Minisondes were recovered, downloaded, maintained, and redeployed. After the final deployment in May, the sensors were left logging data in the piezometers until they were recovered during lower river discharge in July. Battery life varied depending on whether dissolved oxygen was logged. For example, during one deployment, when dissolved oxygen was not measured, power lasted 
approximately 80 days. During a typical deployment when dissolved oxygen was monitored, power lasted approximately 20 days. Other parameters had little effect on battery life. When the battery life of the sensor dropped below 4.3 volts, zero values began to be recorded by some sensors. Zero values recorded due to low power were omitted from the data analysis.

Immediately upon recovery, the batteries inside each Minisonde were exchanged and the data were transferred to a laptop computer. Minisondes were then immediately reprogrammed for a side-by-side deployment adjacent to a laboratory-calibrated Minisonde to help evaluate the accuracy of TDG readings. To collect the side-by-side data, we placed the laboratory-calibrated Minisondes and the recovered Minisondes in the river at an approximate depth of $90 \mathrm{~cm}$. For side-by-side deployments, we logged depth, temperature, salinity, total dissolved gas, dissolved oxygen, and specific conductance every 3 minutes for a minimum of 30 minutes. The Minisondes with stirrers were programmed to have a 1-minute stirrer warm-up prior to sampling. Following side-by-side tests, each total dissolved gas membrane was removed and later transported back to PNNL facilities in Richland, Washington, for quality assurance checks. Following membrane removal, we attached the TDG pressure sensor on the Minisonde to a Druck pressure calibrator (certified to 0.1 psi degree of accuracy) and checked the sensor for accuracy at 100, 200, and $300 \mathrm{mmHG}$. If the pressure reading was off by more than $0.01 \%$ of the span (i.e., the accuracy of the sensor), the unit was recalibrated. A barometric pressure reading was obtained from a laboratory-calibrated Garmin GPS unit and used to reset the pressure sensor. After recalibration, the sensor was checked once more for accuracy at 100, 200, and $300 \mathrm{mmHg}$. We calibrated the dissolved oxygen sensor by attaching a calibration cap filled with $1.3 \mathrm{~cm}$ of deionized water to the Minisonde. The Minisonde was held upright for the duration of the calibration by a clamping laboratory stand. The depth sensor was calibrated by holding the sensor out of the water and setting the depth value to zero. After all calibrations were completed, a new laboratory-tested total dissolved gas membrane was attached to the pressure sensor. Each Minisonde was then given a fully charged set of batteries and reprogrammed for a long-term deployment. All data were backed up using a SanDisk thumb drive.

The membranes that were brought back to PNNL were tested for functionality before they were reused in the field, as outlined in Tanner and Johnston (2001). First, membranes were attached to the pressure sensor on the Minisonde and allowed to equilibrate for 15 minutes. Because of the compressed air between the sensor and the membrane, a functional membrane would initially respond by showing an increase in pressure, then gradually decline, eventually approaching barometric pressure. If the membrane was damaged, there would be no initial pressure increase or a severely reduced one, and the return to barometric pressure would be nearly immediate (Figure 4). In this case, the air would escape quickly through a hole in the membrane rather than gradually be released through the entire membrane. A second functionality test was performed to check the responsiveness of the membrane by inserting the sensor into a beaker of soda water. If the membrane was functioning properly, the sensor should respond by showing a rapid increase in pressure well above barometric pressure. The removal of the sensor from the beaker should show the pressure drop well below barometric pressure and gradually return to barometric pressure after equilibrating for 15 to 30 minutes. A damaged membrane would return to barometric pressure almost immediately after being inserted in the soda water (Figure 4). All membrane test results are listed in Appendix A. Damaged membranes were replaced. One membrane on a control sensor was damaged during a side-by-side quality assurance check, and the data from that control unit were not used in the data analysis. 

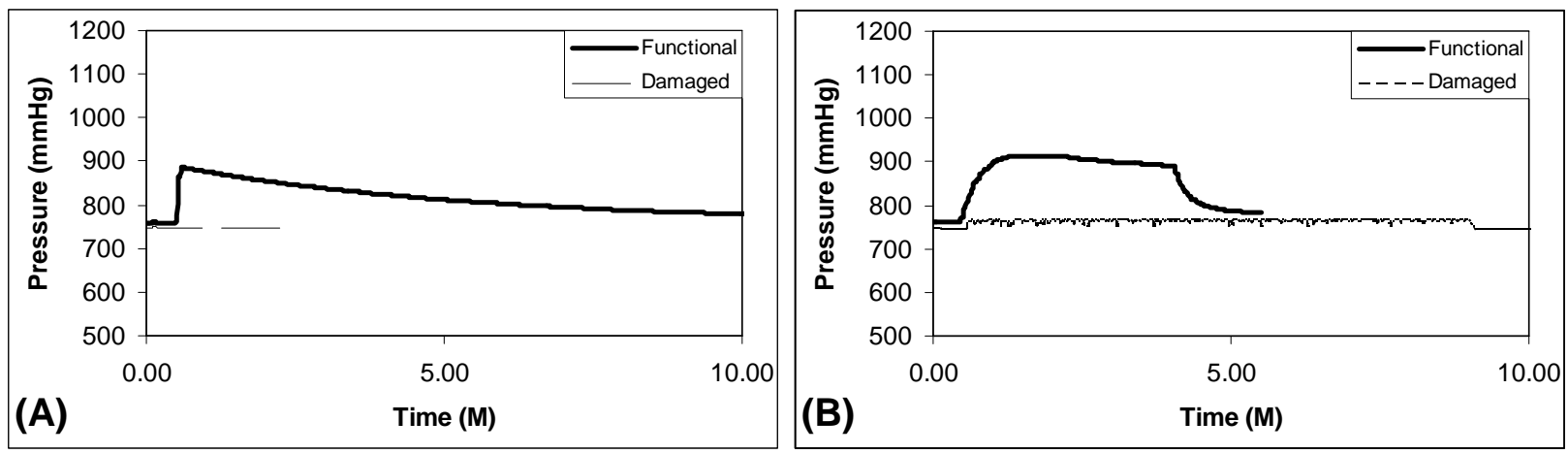

Figure 4. Examples of Functional Versus Damaged Membrane Responses During Quality Assurance Tests Using (A) Compressed Air and (B) Soda Water

We tested the pressure sensor of the laboratory-calibrated Minisonde used for the side-by-side tests after every recovery trip. In the laboratory, the pressure sensor was attached to a certified Druck pressure calibrator and tested for accuracy at 100,200, and $300 \mathrm{mmHg}$. If the pressure reading was off by more than the stated accuracy of $\pm 0.01 \%$ of the span, the unit was recalibrated. We obtained the barometric pressure from the Hanford Meteorological Station (Hanford, Washington) and used it to calibrate the pressure sensor. After recalibration, the sensor was checked once more for accuracy at 100, 200, and $300 \mathrm{mmHg}$. We calibrated the dissolved oxygen sensor and the depth meter in the field. Before each field trip, the barometric pressure from the Hanford Meteorological Station was used to calibrate the Garmin GPS unit, which was used for field calibrations.

Water depth influences TDG saturation and, therefore, the physiological effects on sac fry. If the water depth is greater than the compensation depth (water depth at which gas is in equilibrium with hydrostatic, barometric, and water vapor pressure and saturation level is at 100\%), TDG remains in solution and there are no negative impacts to sac fry. We computed the compensation depth using the equation Tanner and Johnston (2001) modified from Colt (1984):

\section{Compensation Depth in feet $=[T D G$ Pressure $(\mathrm{mmHg})-$ Barometric Pressure $(\mathrm{mmHg})] / 23$}

However, if the water depth is less than the compensation depth and TDG levels are elevated, gas bubbles begin to form, with potential negative impacts to sac fry. When this occurs, there is still a percentage reduction in supersaturation based on the pressure of the water column, but TDG is not fully reduced to $100 \%$. The extent to which it is reduced (and the potential negative impact to sac fry) is a function of the starting TDG concentration and the depth of the water column. We computed the percentage reduction (compensation) in supersaturation based on the pressure of the water column using an equation from Knittel et al. (1980):

\section{Percentage Compensation $=[$ Water Depth $(\mathrm{cm}) \times 0.740(\mathrm{mmHg} / \mathrm{cm}$ water $)]$ 100/Barometric Pressure ( $\mathrm{mmHg}$ )}

We assumed that potential impacts to chum salmon sac fry would occur if the resulting dissolved gas levels were greater than $103 \%$ after the percentage compensation was subtracted from the TDG concentration (McGrath et al. 2006). 
To ensure the representativeness of the TDG values we collected, we compared surface water TDG concentrations obtained from our stations with TDG surface water data collected by the U.S. Geological Survey (USGS) at several lower Columbia River locations during the same time period. The USGS maintains four additional surface water TDG monitoring stations for the U.S. Army Corps of Engineers. One station is at Bonneville Dam; three are downstream of the dam at Cascade Island, Warrendale, and Camas/Washougal (Figure 5). The Bonneville station (BON) is at rkm 235.1, Cascade Island (CCIW) at rkm 234.8, Warrendale (WRNO) at rkm 226.0, and Camas/Washougal (CWMW) at rkm 195.9.

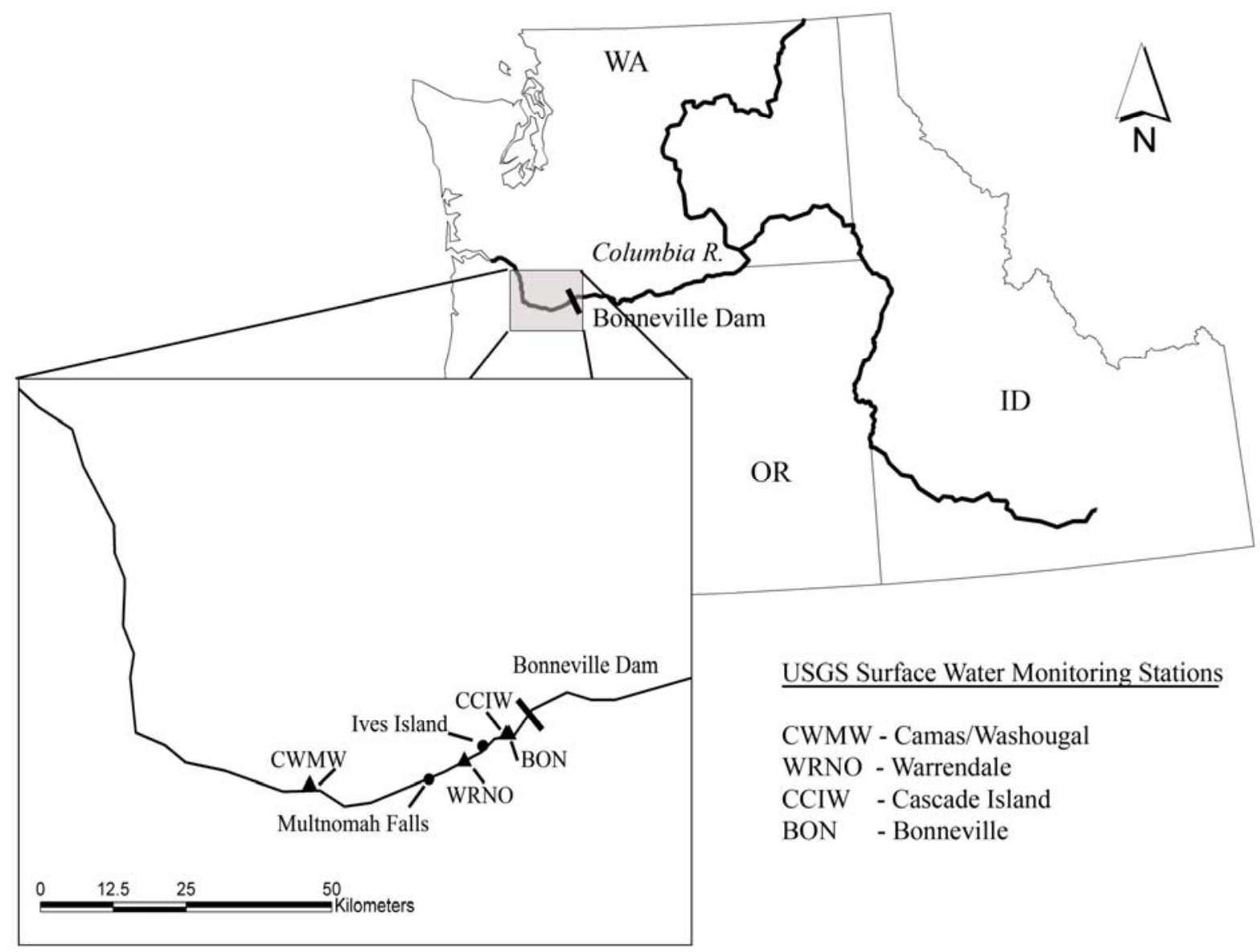

Figure 5. Total Dissolved Gas Monitoring Stations Downstream of Bonneville Dam

As shown in Figure 6, TDG levels at our locations and at USGS stations followed similar trends, with the exception of Cascade Island, where TDG values were consistently higher than at other river sensors. 


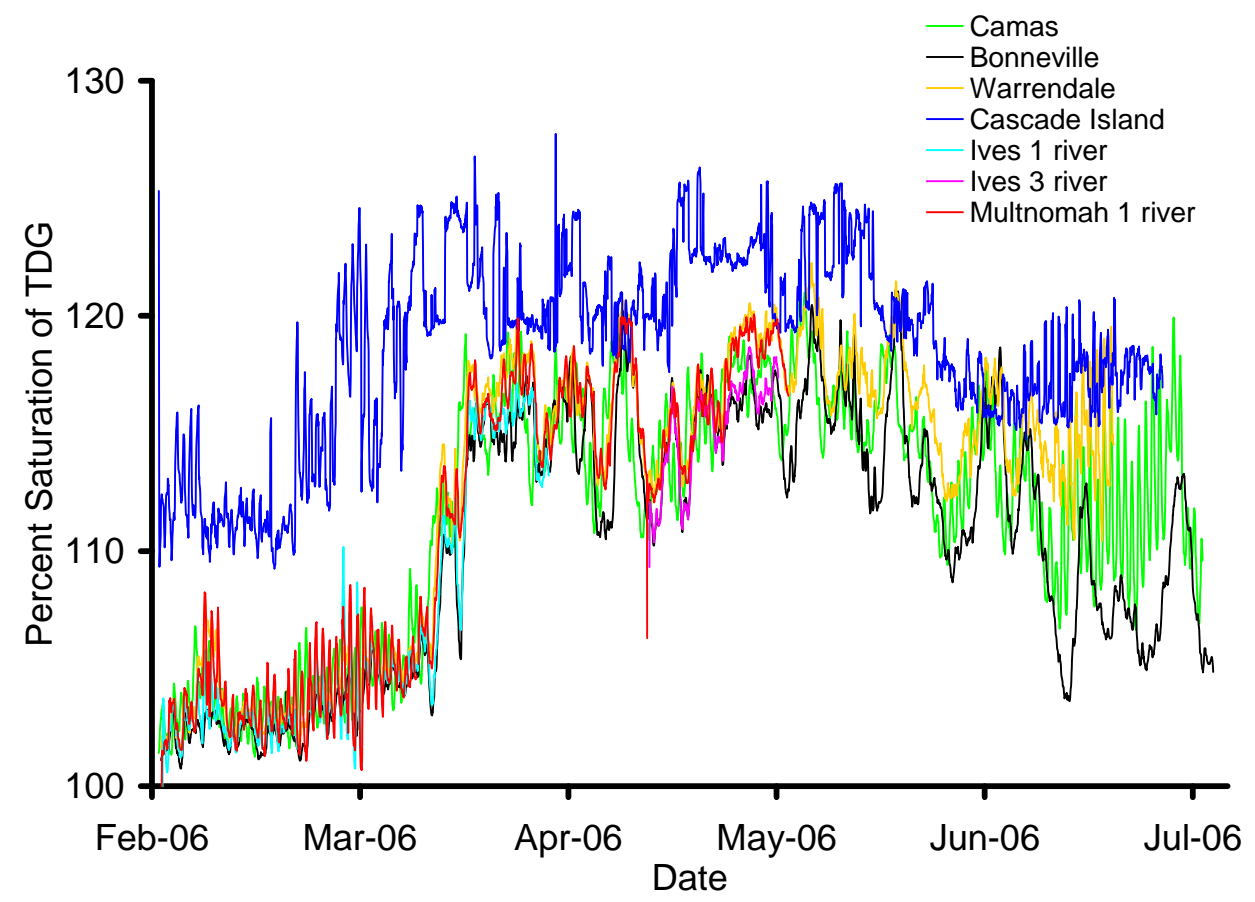

Figure 6. Comparison of 2006 TDG Values Obtained at PNNL Monitoring Stations and USGS Surface Water Monitoring Stations 


\section{Results}

Results of TDG monitoring at the Ives Island and Multnomah Falls sites are documented in this section.

\section{Ives Island Site}

We monitored TDG at Ives 1 river from February 26 through April 23 (Figure 7.A). Uncompensated values of TDG averaged $( \pm \mathrm{SE}) 106.7 \% \pm 0.05 \%$ and ranged from $98.9 \%$ to $117.1 \%$. Depth-compensated TDG values never exceeded 103\% from the beginning of spill through the end of emergence. We assumed chum salmon emergence was complete by May 16, 2006, based on information collected by the Oregon Department of Fish and Wildlife (T. Jones, ODFW, unpublished data).
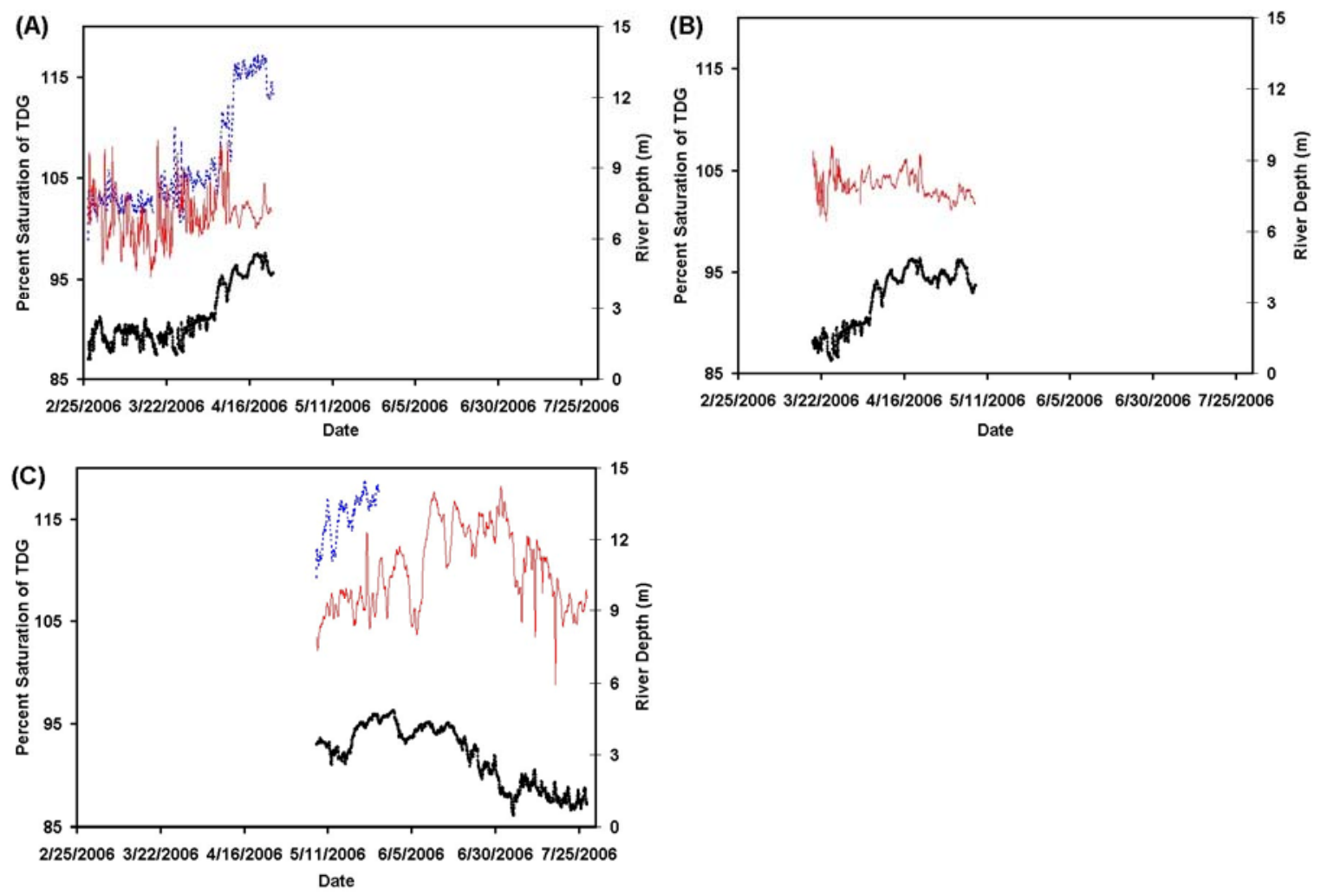

Figure 7. Ives Island Site Total Dissolved Gas Values. (A) Ives pair 1 TDG, (B) Ives 2 hyporheic TDG, and (C) Ives pair 3 TDG. Solid red lines represent uncompensated TDG values for hyporheic sensors; dashed blue lines represent uncompensated TDG values for river sensors. Solid black lines represent river depth.

Ives 1 river TDG values remained relatively constant until April 10, when they rose with the elevated river flows during spring spill operations. At Ives 1 hyporheic, uncompensated values of TDG averaged $( \pm$ SE) $101.5 \% \pm 0.06 \%$ and ranged from $95.2 \%$ to $108.8 \%$, but depth-compensated values never exceeded $103 \%$ (Figure 7.A). The TDG values did not appear to be immediately affected by changes in discharge because they did not rise significantly on or after April 10. 
We monitored TDG at Ives 2 hyporheic from March 19 through May 7 (Figure 7.B). No river sensor was deployed at Ives pair 2. Uncompensated values of TDG averaged $( \pm \mathrm{SE}) 103.6 \% \pm 0.04 \%$ and ranged from $100.0 \%$ to $107.5 \%$. On March 25, the compensation depth exceeded the actual depth $0.4 \%$ of the time. However, compensated TDG saturation values never exceeded 103\% from the beginning of spill through the end of emergence (May 16). The TDG values remained fairly constant throughout the sampling period and did not appear to be immediately affected by changes in discharge.

We monitored TDG at Ives 3 river from May 7 through May 25 (Figure 7.C). Uncompensated values of TDG averaged $( \pm \mathrm{SE}) 115.2 \% \pm 0.11 \%$ and ranged from $100.0 \%$ to $118.7 \%$. The depth-compensated TDG values never exceeded $103 \%$ and appeared to change with varying values of river discharge. We monitored TDG at Ives 3 hyporheic from May 7 through July 27 (Figure 7.C). Uncompensated values of TDG averaged $( \pm \mathrm{SE}) 110.0 \% \pm 0.09 \%$ and ranged from $98.8 \%$ to $118.2 \%$. The compensation depth exceeded the actual depth $4.7 \%$ of the time. Depth-compensated TDG percentage saturation exceeded $103 \%$ from July 1 through July 5 for $2.4 \%$ of the entire sampling period.

Ives 1 river dissolved oxygen levels averaged $( \pm \mathrm{SE}) 12.74 \mathrm{mg} / \mathrm{L} \pm 0.02 \mathrm{mg} / \mathrm{L}$ and ranged from 11.14 to $14.85 \mathrm{mg} / \mathrm{L}$ (Figure 8.A). The dissolved oxygen levels appeared to rise with the increase in flow during spring spill operations. At Ives 1 hyporheic, dissolved oxygen levels averaged $( \pm \mathrm{SE}) 6.83 \mathrm{mg} / \mathrm{L} \pm$ $0.10 \mathrm{mg} / \mathrm{L}$ and ranged from 1.85 to $13.84 \mathrm{mg} / \mathrm{L}$ (Figure 8.A). Through the end of March, Ives 1 hyporheic dissolved oxygen levels fluctuated widely in response to changes in river discharge (Figure 8.B).
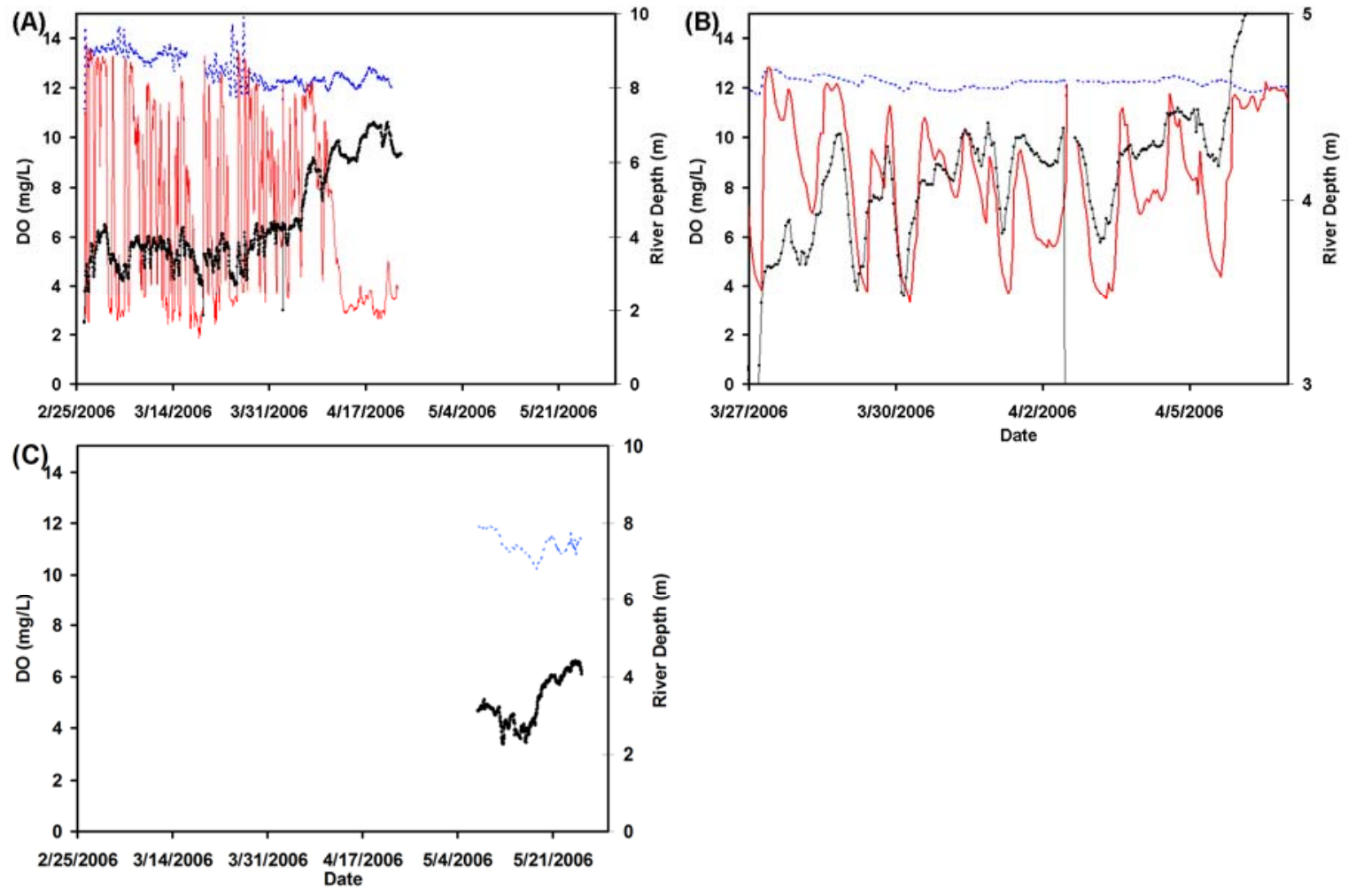

Figure 8. Ives Island Site Dissolved Oxygen Values. (A) Ives pair 1 DO February 26-April 23, (B) Ives pair 1 DO March 27-April 1, and (C) Ives 3 River DO May 7-25. Solid red lines represent DO for hyporheic sensors, and dashed blue lines represent DO for river sensors. Solid black lines represent river depth. 
Data from the Ives 1 hyporheic dissolved oxygen sensor were not used from April 2 through April 22 because the sensor was not calibrated during that time period. The Ives 2 monitoring station had no river sensor, and the Ives 2 hyporheic sensor did not record dissolved oxygen. At Ives 3 river, dissolved oxygen levels averaged $( \pm \mathrm{SE}) 11.16 \mathrm{mg} / \mathrm{L} \pm 0.02 \mathrm{mg} / \mathrm{L}$ and ranged from 10.2 to $11.9 \mathrm{mg} / \mathrm{L}$ (Figure 8.C). The dissolved oxygen levels appeared to rise with the increase in flow during spring spill operations. No dissolved oxygen sensor was installed on the Ives 3 hyporheic data logger.

At Ives 1 river, the temperature averaged $( \pm \mathrm{SE}) 6.7^{\circ} \mathrm{C} \pm 0.05^{\circ} \mathrm{C}$ and ranged from $3.3^{\circ} \mathrm{C}$ to $9.5^{\circ} \mathrm{C}$ (Figures 9.A and 9.B). Values displayed a typical spring warming trend, gradually increasing from February through April. At Ives 1 hyporheic, the temperature averaged $( \pm \mathrm{SE}) 8.1^{\circ} \mathrm{C} \pm 0.04^{\circ} \mathrm{C}$ and ranged from $3.7^{\circ} \mathrm{C}$ to $10.4^{\circ} \mathrm{C}$ (Figure 9.A). Values fluctuated widely until March 27, then uniformly trended upward. Hyporheic temperature fluctuations prior to April 10 closely matched river stage fluctuations (Figure 9.B). Lower water depth before April 10 allowed for more interaction between groundwater and surface water and also for greater heating due to solar inputs; both factors likely influenced the large temperature fluctuations during this time period. The temperature at Ives 2 hyporheic averaged $( \pm \mathrm{SE})$ $9.2^{\circ} \mathrm{C} \pm 0.02^{\circ} \mathrm{C}$ and ranged from $6.1^{\circ} \mathrm{C}$ to $10.7^{\circ} \mathrm{C}$. Hyporheic temperature trends at Ives 2 were similar to those at Ives 1, fluctuating widely with changes in river stage until approximately March 27 and then uniformly trending upward (Figures 9.C and 9.D). At Ives 3 river, the temperature averaged $( \pm \mathrm{SE})$ $13.3^{\circ} \mathrm{C} \pm 0.05^{\circ} \mathrm{C}$ and ranged from $11.6^{\circ} \mathrm{C}$ to $15.1^{\circ} \mathrm{C}$. Values continued to increase gradually throughout the month of May (Figure 9.E). The temperature at Ives 3 hyporheic averaged $( \pm \mathrm{SE}) 13.3^{\circ} \mathrm{C} \pm 0.03^{\circ} \mathrm{C}$ and ranged from $11.6^{\circ} \mathrm{C}$ to $15.1^{\circ} \mathrm{C}$.

At Ives 1 river, specific conductance averaged $( \pm \mathrm{SE}) 188.4 \mu \mathrm{S} / \mathrm{cm} \pm 0.4 \mu \mathrm{S} / \mathrm{cm}$ and ranged from 143 to $207 \mu \mathrm{S} / \mathrm{cm}$ (Figure 10.A). Data from February 26 through March 19 were collected using an inappropriate data range and were excluded. At Ives 1 hyporheic, the specific conductance averaged ( $\pm \mathrm{SE}$ ) $171.0 \mu \mathrm{S} / \mathrm{cm} \pm 0.5 \mu \mathrm{S} / \mathrm{cm}$ and ranged from 149 to $200 \mu \mathrm{S} / \mathrm{cm}$ (Figure 10.A). Despite relatively small differences between the specific conductance of river water and hyporheic water, hyporheic specific conductance fluctuated with changes in river stage similar to the other water quality parameters we measured (Figure 10.B).

A similar although less pronounced pattern was observed in data collected from Ives 2 hyporheic and Ives 3 hyporheic. At Ives 2 hyporheic, specific conductance averaged $( \pm \mathrm{SE}) 150.1 \mu \mathrm{S} / \mathrm{cm} \pm 0.25 \mu \mathrm{S} / \mathrm{cm}$ and ranged from 139 to $186 \mu \mathrm{S} / \mathrm{cm}$ (Figure 10.C). The specific conductance at Ives 3 river averaged $( \pm \mathrm{SE}) 142.3 \mu \mathrm{S} / \mathrm{cm} \pm 0.23 \mu \mathrm{S} / \mathrm{cm}$ and ranged from 130 to $150 \mu \mathrm{S} / \mathrm{cm}$ (Figure 10.D). At Ives 3 hyporheic, the specific conductance averaged $( \pm \mathrm{SE}) 152.1 \mu \mathrm{S} / \mathrm{cm} \pm 0.15 \mu \mathrm{S} / \mathrm{cm}$ and ranged from 116 to $164 \mu \mathrm{S} / \mathrm{cm}$ (Figure 10.D). 

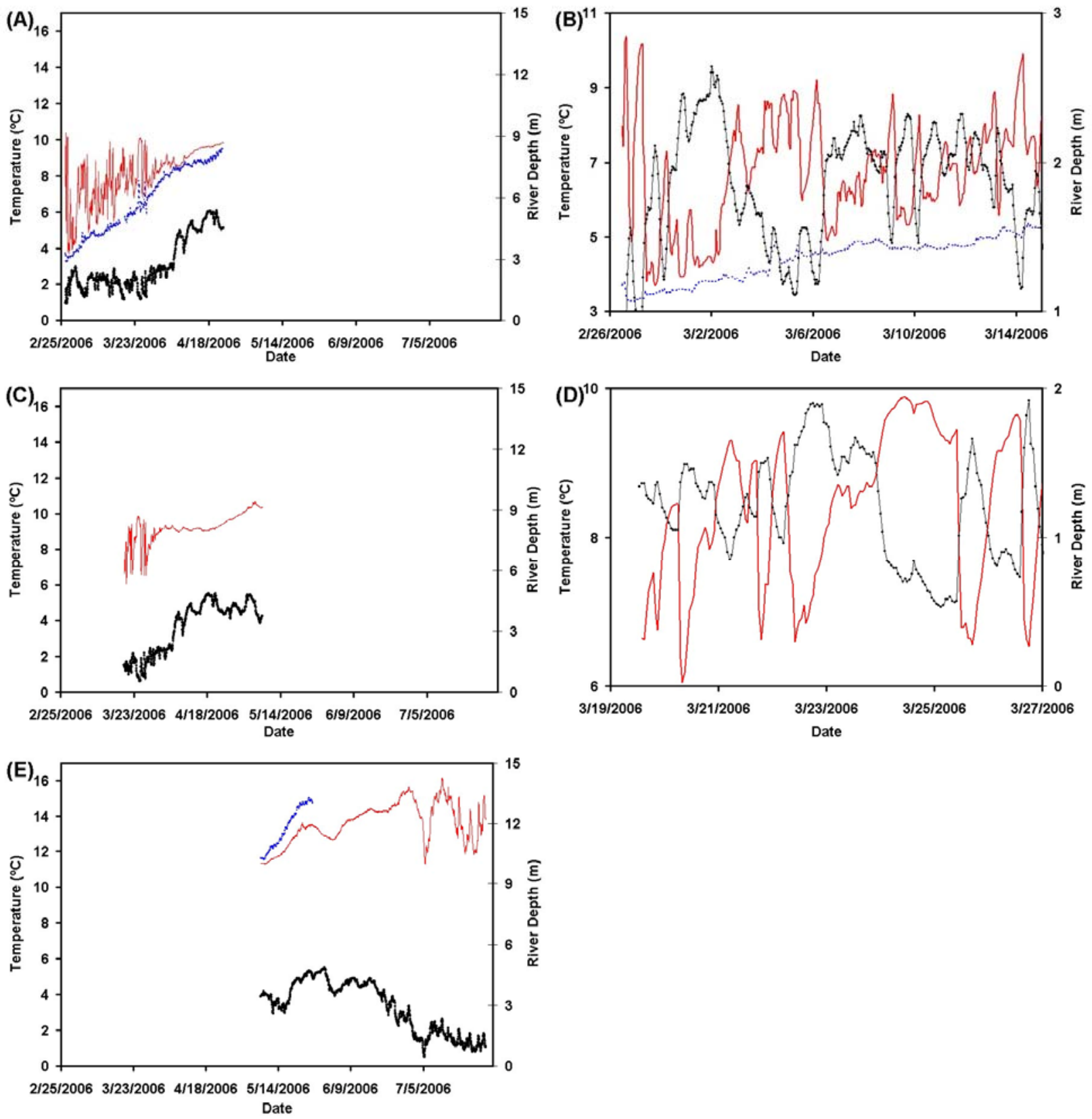

Figure 9. Ives Island Site Temperature Values. (A) Ives pair 1 temperature February 26-April 23, (B) Ives pair 1 temperature February 26-March 17, (C) Ives 2 hyporheic temperature March 20-May 7, (D) Ives 2 hyporheic temperature March 19-27, and (E) Ives pair 3 temperature May 7-July 27. Solid red lines represent temperature for hyporheic sensors, and dashed blue lines represent temperature for river sensors. Solid black lines represent river depth. 

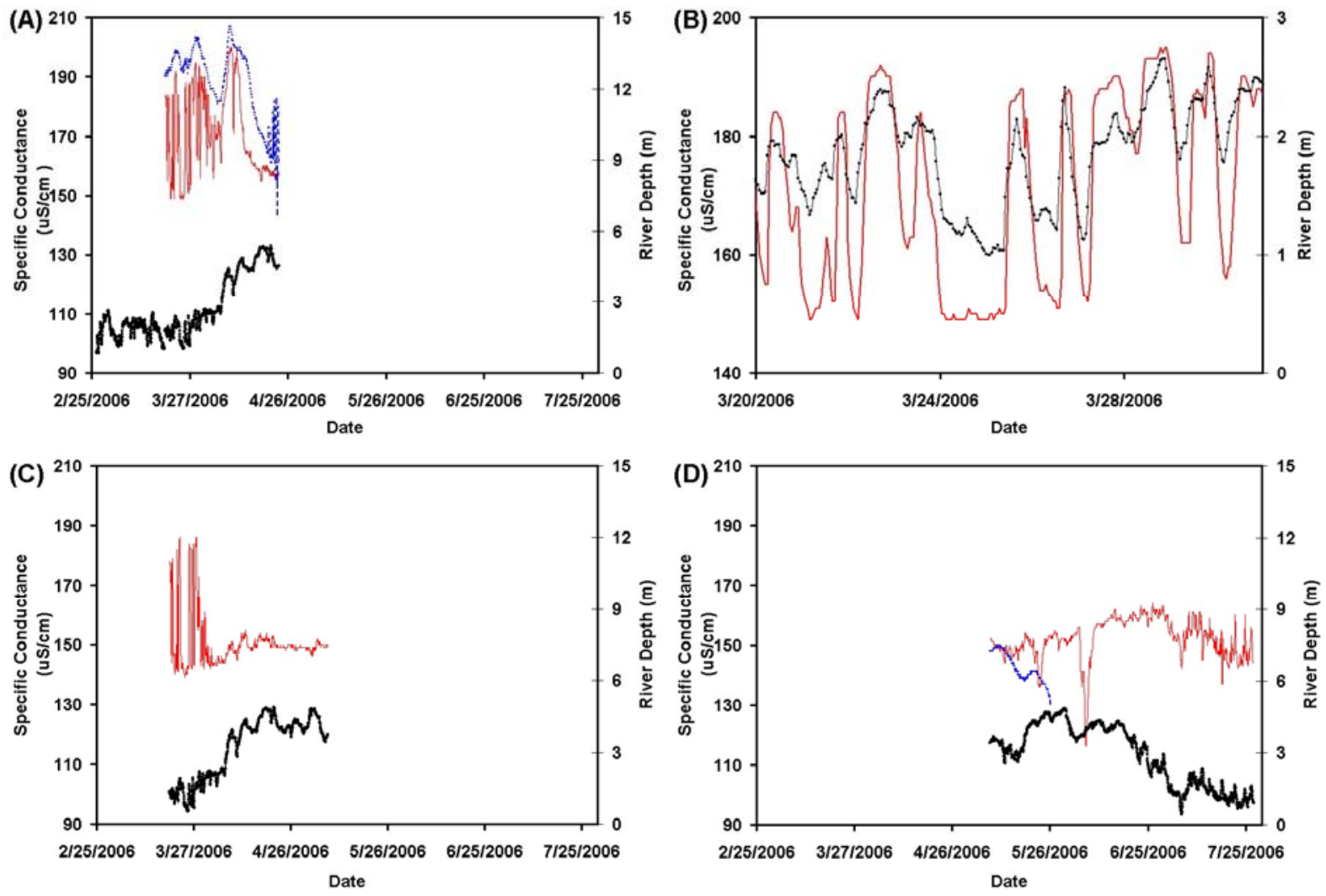

Figure 10. Ives Island Site Specific Conductance Values. (A) Ives pair 1 specific conductance from March 19-April 23, (B) Ives 1 hyporheic specific conductance from March 20-31, (C) Ives pair 2 hyporheic specific conductance from March 20-May 7, and (D) Ives pair 3 specific conductance from May 9-July 27. Solid red lines represent specific conductance for hyporheic sensors, and dashed blue lines represent specific conductance for river sensors. Solid black lines represent river depth.

\section{Multnomah Falls Site}

We monitored TDG levels at Multnomah Falls pair 1 from February 26 through May 27 and Multnomah Falls 2 hyporheic from May 7 through May 28. Spring spill operations began on April 10, and chum salmon emergence was completed by May 16 (T. Jones, ODFW, unpublished data). Uncompensated values in Multnomah Falls 1 and 2 hyporheic were generally less than 103\%; therefore, there was no need to calculate depth-compensated values (Figures 11.A and 11.B). For Multnomah Falls 1 river, uncompensated values of TDG averaged $( \pm \mathrm{SE}) 110.8 \% \pm 0.14 \%$ and ranged from $98.5 \%$ to $120.1 \%$. The compensation depth exceeded the actual depth $33.8 \%$ of the time. However, the compensated values never exceeded 103\%. Multnomah Falls pair 1 river TDG values increased with higher river levels (Figure 11.A). At Multnomah Falls 1 hyporheic, uncompensated values of TDG averaged ( \pm SE) $100.4 \% \pm 0.05 \%$ and ranged from $94.8 \%$ to $104.7 \%$. The TDG values appeared to be uninfluenced by discharge, as shown by the relatively steady TDG levels during spring spill operations. At Multnomah Falls 2 hyporheic, uncompensated values of TDG averaged $( \pm \mathrm{SE}) 97.8 \% \pm 0.04 \%$ and ranged from $95.4 \%$ to $99.5 \%$. TDG was monitored at Multnomah Falls 2 hyporheic for only 3 weeks. Values there were similar to those measured at Multnomah Falls 1 hyporheic during the same time period (Figure 11.B). 

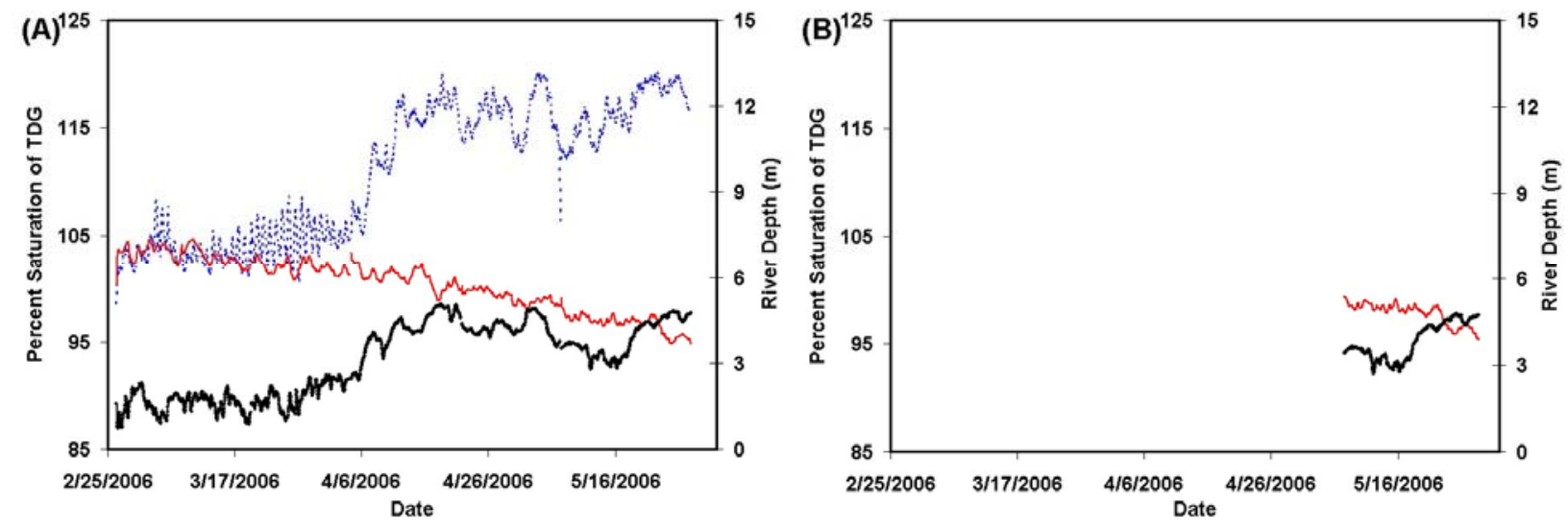

Figure 11. Multnomah Falls Site Total Dissolved Gas Values. (A) Multnomah Falls pair 1 TDG; (B) Multnomah Falls 2 hyporheic TDG. Solid red lines represent uncompensated TDG values for hyporheic sensors, and dashed blue lines represent uncompensated TDG values for river sensors. Solid black lines represent river depth.

At Multnomah Falls 1 river, dissolved oxygen levels averaged $( \pm \mathrm{SE}) 12.58 \mathrm{mg} / \mathrm{L} \pm 0.02 \mathrm{mg} / \mathrm{L}$ and ranged from 10.06 to $15.73 \mathrm{mg} / \mathrm{L}$ (Figure 12.A). During mid to late March, Multnomah Falls river dissolved oxygen levels fluctuated with changing river stage (Figure 12.B). At Multnomah Falls 1 hyporheic, dissolved oxygen levels averaged $( \pm \mathrm{SE}) 9.91 \mathrm{mg} / \mathrm{L} \pm 0.009$ and ranged from 7.81 to $11.7 \mathrm{mg} / \mathrm{L}$ (Figure 12.A). At Multnomah Falls 2 hyporheic, dissolved oxygen levels averaged $( \pm \mathrm{SE})$ $8.81 \pm 0.009 \mathrm{mg} / \mathrm{L}$ and ranged from 8.44 to $9.18 \mathrm{mg} / \mathrm{L}$ (Figure 12.C). Dissolved oxygen was monitored at Multnomah Falls 2 hyporheic for only 3 weeks. Values there were similar to, but much less variable than, those measured at Multnomah Falls 1 hyporheic during the same time period.

At Multnomah Falls 1 river, the temperature averaged $( \pm \mathrm{SE}) 8.9^{\circ} \mathrm{C} \pm 0.07^{\circ} \mathrm{C}$ and ranged from $3.5^{\circ} \mathrm{C}$ to $15.0^{\circ} \mathrm{C}$ (Figure 13.A). Values displayed a typical spring warming trend, gradually increasing from February through April. At Multnomah Falls 1 hyporheic, the temperature averaged $( \pm \mathrm{SE}) 7.8^{\circ} \mathrm{C} \pm$ $0.006^{\circ} \mathrm{C}$ and ranged from $6.6^{\circ} \mathrm{C}$ to $8.1^{\circ} \mathrm{C}$. Temperatures trended slightly downward over the sampling period (Figure 13.A). At Multnomah Falls 2 hyporheic, the temperature averaged $( \pm \mathrm{SE}) 8.2^{\circ} \mathrm{C} \pm 0.003^{\circ} \mathrm{C}$ and ranged from $8.0^{\circ} \mathrm{C}$ to $8.3^{\circ} \mathrm{C}$. Temperatures trended slightly downward over the sampling period (Figure 13.B).

At Multnomah Falls 1 river, specific conductance averaged $( \pm \mathrm{SE}) 159.0 \mu \mathrm{S} / \mathrm{cm} \pm 0.51 \mu \mathrm{S} / \mathrm{cm}$ and ranged from 96 to $199 \mu \mathrm{S} / \mathrm{cm}$ (Figure 14.A). At Multnomah Falls 1 hyporheic, the specific conductance averaged ( $\pm \mathrm{SE}$ ) $40.5 \mu \mathrm{S} / \mathrm{cm} \pm 0.04 \mu \mathrm{S} / \mathrm{cm}$ and ranged from 39 to $44 \mu \mathrm{S} / \mathrm{cm}$ (Figure 14.A). At Multnomah Falls 2 hyporheic, specific conductance averaged $( \pm \mathrm{SE}) 38.0 \mu \mathrm{S} / \mathrm{cm} \pm 0.006 \mu \mathrm{S} / \mathrm{cm}$ and ranged from 37 to $39 \mu \mathrm{S} / \mathrm{cm}$ (Figure 14.B). 

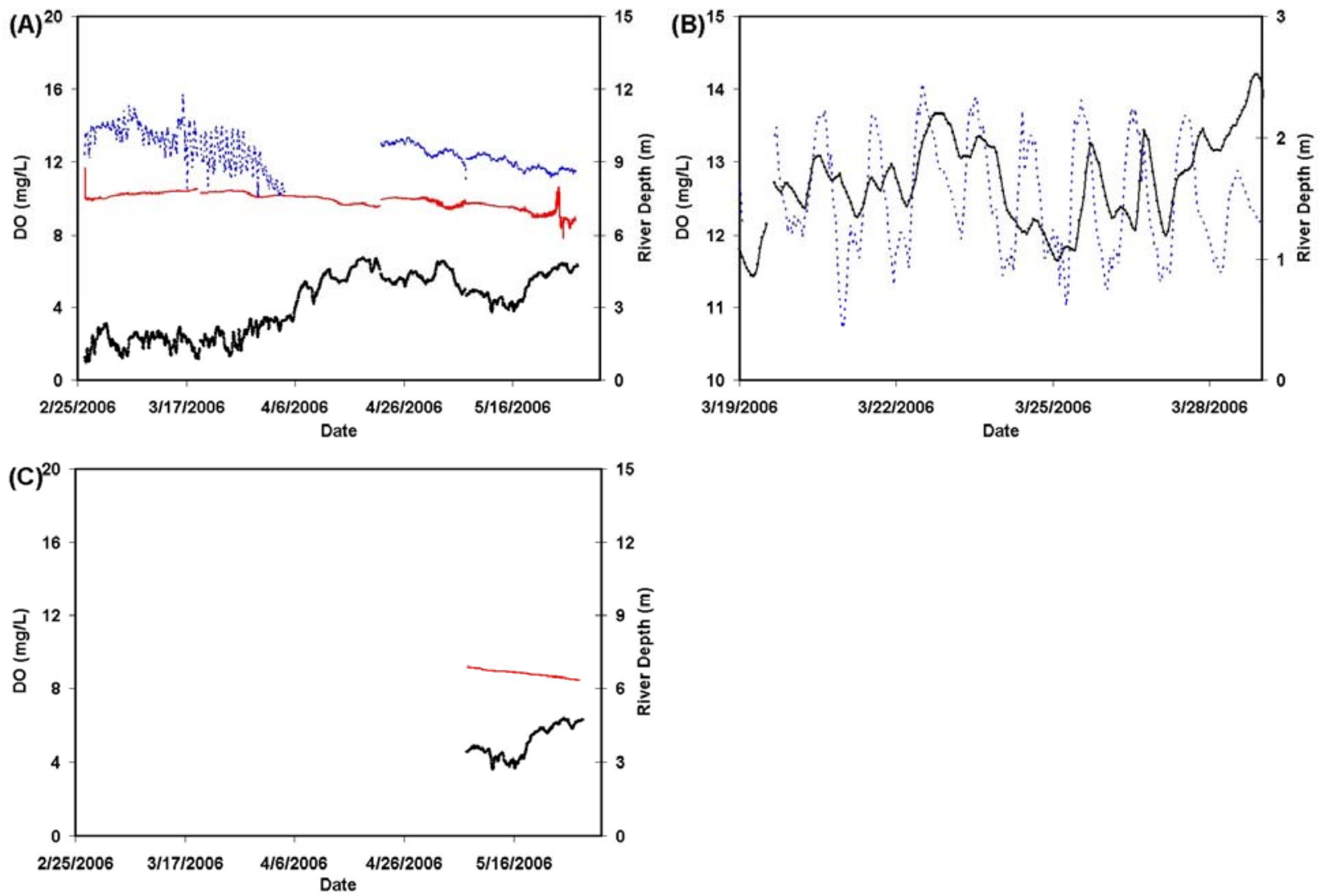

Figure 12. Multnomah Falls Site Dissolved Oxygen Values. (A) Multnomah Falls pair 1 DO February 26-May 7, (B) Multnomah Falls 1 river DO March 19-29, and (C) Multnomah Falls 2 hyporheic DO May 7-27. Solid red lines represent DO values for hyporheic sensors, and dashed blue lines represent DO for river sensors. Solid black lines represent river depth.
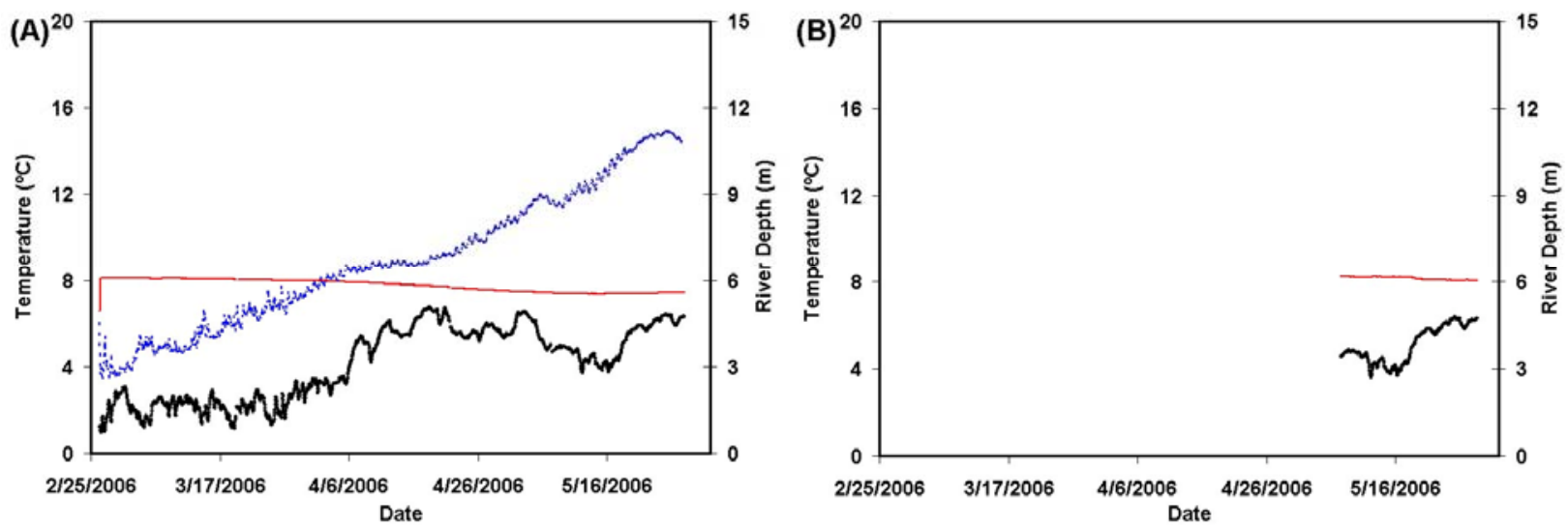

Figure 13. Multnomah Falls Site Temperature Values. (A) Multnomah Falls pair 1 temperature February 26-May 27; (B) Multnomah Falls 2 hyporheic temperature May 7-27. Solid red lines represent temperature values for hyporheic sensors, and dashed blue lines represent temperature values for river sensors. Solid black lines represent river depth. 

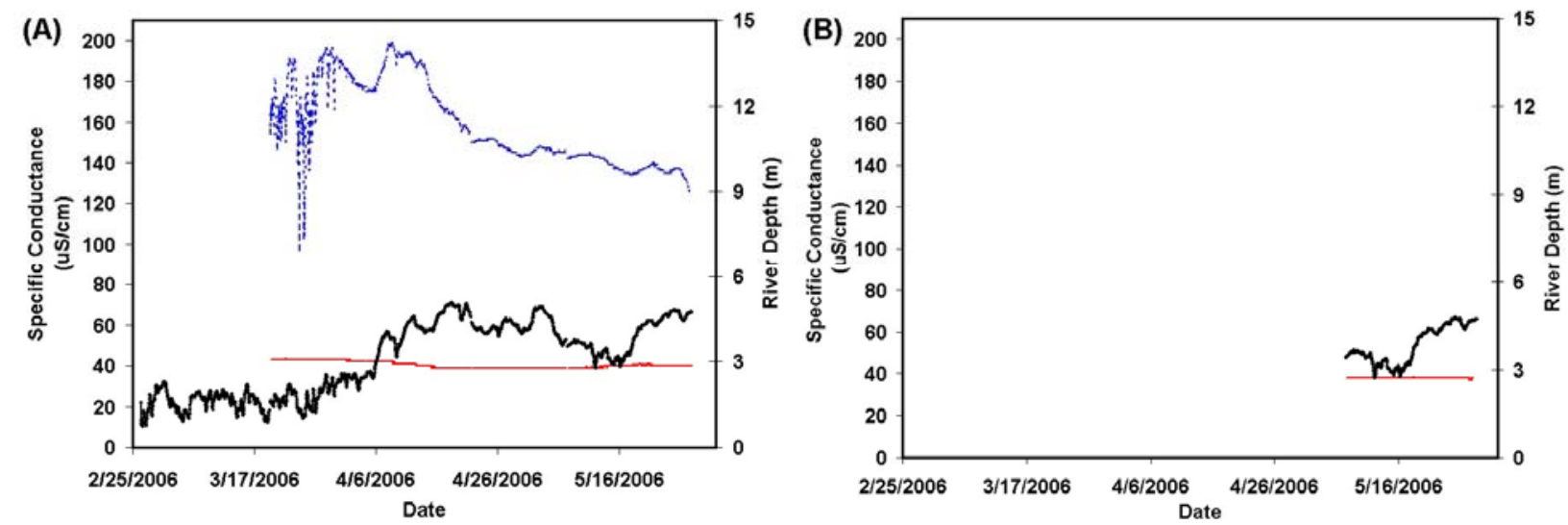

Figure 14. Multnomah Falls Site Specific Conductance Values. (A) Multnomah Falls pair 1 specific conductance from February 26-May 27; (B) Multnomah Falls 2 hyporheic specific conductance from May 7-27. Solid red lines represent specific conductance for hyporheic sensors, and dashed blue line represents specific conductance for river sensors. Solid black lines represent river depth. 


\section{Discussion}

The response of water quality to fluctuation in river stage was significantly different at the Ives Island site compared to the Multnomah Falls site. At Multnomah Falls, hyporheic responses were relatively stable despite significant daily fluctuations in river concentrations of total dissolved gas, dissolved oxygen, and temperature (Figures 11 through 14). In contrast, especially during the early spring prior to the initiation of spill operations on April 10, Ives hyporheic values fluctuated widely in response to daily changes in river TDG, dissolved oxygen, temperature, and specific conductance (Figures 7 through 10). The differences between hyporheic water and river water suggest a groundwater influence at both locations, which is not surprising - chum salmon spawn at both sites, and chum salmon generally select spawning areas where relatively warm water upwells into the river (Geist et al. 2002). The relative stability of hyporheic water quality characteristics at Multnomah Falls suggests that river discharge fluctuations have little effect on water quality at egg pocket depth there. The stable water quality signature suggests a relatively constant source of groundwater or spring water discharge there (Shepherd et al. 1986; Crisp 1990). This is supported further by similarities between the water chemistry of Multnomah Creek upstream from our study site and the hyporheic zone at our study site. We measured water quality parameters in Multnomah Creek on October 20, 2006, and found average values of temperature $9.7^{\circ} \mathrm{C}$, dissolved oxygen $11.1 \mathrm{mg} / \mathrm{L}$, and specific conductance $31.9 \mu \mathrm{S} / \mathrm{cm}$, values similar to earlier results from Multnomah Falls hyporheic (Figures 12 through 14). The similarity suggests that water from Multnomah Creek is flowing through the hyporheic zone and later discharging into the Columbia River through springs where chum salmon are spawning. In contrast, the relative instability of hyporheic water quality characteristics near Ives Island suggests that the direction of flux between hyporheic water and the river is reversed with river stage fluctuations. This condition has been observed before in the Columbia River associated with large and frequent fluctuations in river stage (Arntzen et al. 2006).

When river discharge increased significantly (approximately when spring spill operations began April 10), dissolved oxygen, temperature, and specific conductance all became much more stable in the Ives Island area. It is likely that higher river flows dominated hyporheic water flux and that changes to river stage had a lessened influence on flux in the hyporheic zone. The TDG levels at Ives 3 hyporheic displayed the most variability and appeared to be influenced by increases in discharge. This sensitivity could be attributed to sediment permeability. If the riverbed is highly permeable, river water could easily be forced below the riverbed surface into the hyporheic zone, especially when the river stage is higher (Arntzen et al. 2006).

Our water quality results for the Ives Island site are similar to those from a previous study that investigated water quality in the hyporheic zone and the river within the Ives Island area (Geist et al. 2002). One of the locations they studied (Cluster 3) was situated very close to Ives pair 1 from our study, approximately $10 \mathrm{~m}$ toward the thalweg of the channel from Ives pair 1. Upwelling was found by Geist et al. (2002) to be the most pronounced at that location. Hyporheic temperature in cluster 3 averaged $6.7^{\circ} \mathrm{C}$ higher than the river. In our study, at Ives pair 1 the average hyporheic temperature was $1.4^{\circ} \mathrm{C}$ warmer than river temperature. Geist et al. (2002) measured hyporheic dissolved oxygen levels of $5.7 \mathrm{mg} / \mathrm{L}$ compared to $11.2 \mathrm{mg} / \mathrm{L}$ for the river at Cluster 3. Our results at Ives pair 1 were similar (average dissolved oxygen levels were $6.8 \mathrm{mg} / \mathrm{L}$ for hyporheic and $12.7 \mathrm{mg} / \mathrm{L}$ for river). Geist et al. (2002) found specific conductance ranged from 132 to $164 \mu \mathrm{S} / \mathrm{cm}$ in the hyporheic zone and the river, with no 
statistical difference between the two, although specific conductance was $10 \mu \mathrm{S} / \mathrm{cm}$ higher in the river at Cluster 3 than in the hyporheic zone there. In our study, we found that river values at Ives pair 1 averaged $17.4 \mu \mathrm{S} / \mathrm{cm}$ higher than hyporheic values, although both river and hyporheic values were approximately $30-40 \mu \mathrm{S} / \mathrm{cm}$ greater than values reported by Geist et al. (2002).

We considered TDG levels during times of voluntary and involuntary spill by comparing hourly data from Ives pair 3 to Bonneville Dam operations. From April through August, daily target spills (provided to us by the USACE) ranged from 70 to $150 \mathrm{kcfs}$. Involuntary spill occurred when the actual spill exceeded the target spill. Mean uncompensated TDG was $109.9 \%$ during voluntary spill and $110.2 \%$ during involuntary spill. There was no statistical difference between TDG during voluntary versus involuntary spill $(\alpha=0.05)$. TDG levels higher than the allowable criterion might be expected during involuntary spill. However, our findings suggest that TDG levels producing potentially toxic conditions to incubating chum salmon sac fry may be occurring during voluntary spill periods as well, during lowwater years when available depth compensation is limited.

Previous studies have shown that exposure to TDG levels higher than $103 \%$ for even short periods of time can affect sac fry (Fidler and Miller 1997). Depth-compensated TDG levels exceeded 103\% at Ives 3 hyporheic, where levels remained elevated above $103 \%$ for a 12-hour period on July 1-2, a 12-hour period on July 2-3, a 5-hour period on July 3, and a 17-hour period on July 4-5. Depth-compensated TDG never exceeded 103\% at Ives pair 1 and 2 or at Multnomah Falls pair 1 and 2 hyporheic. Water levels during 2006 remained high enough so that sac fry were not affected by TDG levels. However, USACE data show times during previous, lower-water years (e.g., 2004 and 2005) when the water depth dropped below the compensation depth (Figure 15; USACE 2006). During 2005, water depth dropped below the compensation depth 51\% of the time from March 6 through 20 and 39\% of the time from April 4 through May 5 (Arntzen et al. 2007).

Given a lower water year, pre-emergent sac fry could be negatively affected by sustained elevated levels of TDG in the hyporheic zone as we observed in this study. However, whether these elevated levels of TDG will result in negative impacts is purely speculative because no specific studies of elevated TDG have been conducted on chum salmon sac fry (McGrath et al. 2006). We recommend that research be conducted to evaluate the effects of total dissolved gas on incubating chum salmon sac fry. We also recommend that monitoring of total dissolved gas at Ives Island and Multnomah Falls be conducted during normal- to low-water years (when depth compensation will be reduced and impacts to sac fry would be maximized). 

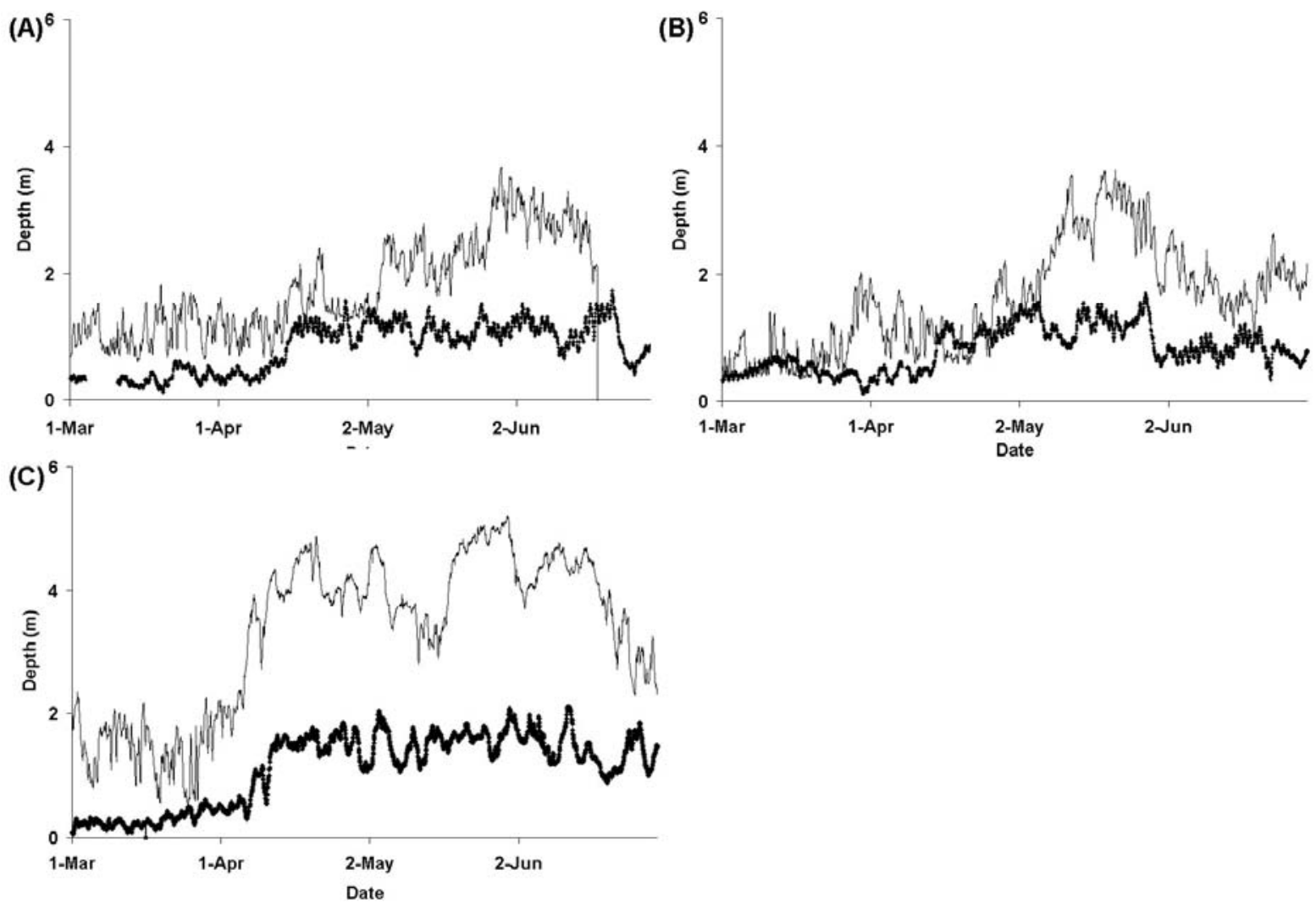

Figure 15. Water Depth Above the Egg Pocket and the Compensation Depth Near Ives Pair 1 During Spring Runoff in (A) 2004, (B) 2005, and (C) 2006. Water level data collected previously near Ives pair 1 show that TDG concentrations would likely not be depth-compensated below levels safe for chum salmon fry during low-water years. The thin black lines represent water depth above the egg pocket at Ives pair 1. Thick dotted black lines represent compensation depth. 



\section{References}

Arntzen EV, DR Geist, and PE Dresel. 2006. "Effects of fluctuating river flow on groundwater/surface water mixing in the hyporheic zone of a regulated, large cobble bed river." River Research and Applications 22(8):937-946.

Arntzen EV, RP Mueller, CJ Murray, Y-J Bott, JL Panther, DR Geist, and TP Hanrahan. 2007. Evaluation of Salmon Spawning Below the Four Lowermost Columbia River Dams - 2006 Annual Report. Prepared by Pacific Northwest National Laboratory for the U.S. Department of Energy, Bonneville Power Administration, Portland, Oregon.

Colt J. 1984. "Computation of dissolved gas concentrations in water as functions of temperature, salinity, and pressure." American Fisheries Society Special Publication 14, American Fisheries Society, Bethesda, Maryland.

Crisp DT. 1990. "Water temperature in a stream gravel bed and implications for salmonid incubation." Freshwater Biology 23:601-612.

Ebel WJ. 1969. "Supersaturation of nitrogen in the Columbia River and its effect on salmon and steelhead trout." United States Fisheries Service Fishery Bulletin 68:1-11.

Ebel WJ and HL Raymond. 1976. "Effect of atmospheric gas supersaturation on salmon and steelhead trout of the Snake and Columbia rivers." Marine Fisheries Review 38(7):1-14.

EPA (U.S. Environmental Protection Agency). 1987. Quality Criteria for Water 1986 [the Gold Book]. EPA 440586001, U.S. Environmental Protection Agency, Washington, D.C.

Fidler LE and SB Miller. 1997. British Columbia Water Quality Guidelines for the Protection of Aquatic Biota from Dissolved Gas Supersaturation - Technical Report. Ministry of Environment, Lands and Parks, Environment Canada, Department of Fisheries and Oceans, Vancouver, British Columbia, Canada.

Geist DR, TP Hanrahan, EV Arntzen, GA McMichael, CJ Murray, and Y-J Chien. 2002.

"Physicochemical characteristics of the hyporheic zone affect redd site selection by Chum salmon and fall Chinook salmon in the Columbia River." North American Journal of Fisheries Management 22:10771085.

Geist DR, MC Joy, DR Lee, and T Gonser. 1998. "A method for installing piezometers in large cobble bed rivers." Ground Water Monitoring and Remediation 18(1):78-82.

Hydrolab Corporation. 2006. Hydrolab DS5X, DS5, and MS5 Water Quality Multiprobes User Manual. Edition 3. Hydrolab Corporation, Austin, Texas.

Knittel GA, Chapman, and RR Garton. 1980. "Effects of hydrostatic pressure on steelhead survival in air-supersaturated water." Transactions of the American Fisheries Society 109:755-759.

McGrath K, E Dawley, and DR Geist. 2006. Total Dissolved Gas Effects on Fishes of the Lower Columbia River. PNNL-15525, Pacific Northwest National Laboratory, Richland, Washington. 
NAS/NAE (National Academy of Science/National Academy of Engineering). 1973. Water Quality Criteria 1972. EPA-R-73-033, U.S. Environmental Protection Agency, Washington, D.C.

NOAA (National Oceanographic and Atmospheric Administration). 1995. Item 2. Pages 104-110 in Endangered Species Act - Section 7 Consultation, Biological Opinion, Federal Columbia River Power System (FCRPS). National Oceanic and Atmospheric Administration, National Marine Fisheries Service, Northwest Regional Office, Seattle, Washington.

NOAA (National Oceanographic and Atmospheric Administration). 2000. "Risk Assessment for Spill Program Described in 2000 Draft Biological Opinion.” Appendix E in Endangered Species Act Section 7 Biological Opinion on the Reinitiation of Consultation on Operation of the Federal Columbia River Power System, Including the Juvenile Fish Transportation Program, and 19 Bureau of Reclamation Projects in the Columbia Basin. Available at http://seahorse.nmfs.noaa.gov/pls/pctspub/sxn7.pcts_upload.summary_list_biop?p_id=12342.

Orghidan T. 1959. "Ein neuer Lebensraum des unterirdischen Wassers, der hyporheische Biotop." Archiv für Hydrobiologie 55:392-414.

Shepherd BG, GF Hartman, and WJ Wilson. 1986. "Relationships between stream and intragravel temperatures in coastal drainages, and some implications for fisheries workers." Canadian Journal of Fisheries and Aquatic Sciences 43:1818-1822.

Tanner DQ and MW Johnston. 2001. Data-Collection Methods, Quality-Assurance Data, and Site Considerations for Total Dissolved Gas Monitoring, Lower Columbia River, Oregon and Washington, 2000. 01-4005, U.S. Department of the Interior, U.S. Geological Survey, Portland, Oregon.

USACE (U.S. Army Corps of Engineers). “Water Quality Parameters, 1997, 2000-2006.” U.S. Army Corps of Engineers. Available at http://www.nwd-wc.usace.army.mil/ftppub/water_quality.

USACE (U.S. Army Corps of Engineers), Bureau of Reclamation, and Bonneville Power Administration. 2004. Final updated proposed action for the FCRPS biological opinion remand. November 24, 2004. Available at http://www.salmonrecovery.gov/reports_and_papers/biop_remand/docs/upa_final/FinalUPANov242004. pdf.

Weitkamp DE and M Katz. 1980. "A review of dissolved gas supersaturation literature." Transactions of the American Fisheries Society 109:659-702. 


\section{Appendixes}

Appendix A provides all data from quality assurance tests conducted on the total dissolved gas sensor membranes used in data collection. Appendix B contains all the water quality data collected during the 2006 monitoring period. Appendixes A and B are contained on the compact disk (CD) provided with the hardcopy version of this report on the inside back cover. 